NBER WORKING PAPER SERIES

\title{
THE AGGREGATE EFFECTS OF HEALTH \\ INSURANCE: EVIDENCE FROM THE INTRODUCTION OF MEDICARE
}

\author{
Amy Finkelstein \\ Working Paper 11619 \\ http://www.nber.org/papers/w11619 \\ NATIONAL BUREAU OF ECONOMIC RESEARCH \\ 1050 Massachusetts Avenue \\ Cambridge, MA 02138 \\ September 2005
}

I am grateful to Daron Acemoglu, Tim Bresnahan, David Cutler, Joe Doyle, Mark Duggan, Sue Dynarski, Alan Garber, Michael Greenstone, Jon Gruber, Brian Jacob, Ben Jones, Chad Jones, Melissa Kearney, Katherine Levit, Jeff Liebman, Adriana Lleras-Muney, Erzo Luttmer, Ellen Meara, Robin McKnight, Joe Newhouse, Ben Olken, Jim Poterba, Sarah Reber, Jon Skinner, Scott Stern, Melissa Thomasson, and Vic Fuchs for helpful comments and discussions, to Mireya Almazan, Prashanth Bobba, Erkut Kucukboyaci, Sarah Levin, Sharon Schaff, and especially Erin Strumpf for outstanding research assistance, and to the NIA (P30-AG12810) and the Harvard Milton Fund for financial support. The views expressed herein are those of the author(s) and do not necessarily reflect the views of the National Bureau of Economic Research.

(C)2005 by Amy Finkelstein. All rights reserved. Short sections of text, not to exceed two paragraphs, may be quoted without explicit permission provided that full credit, including () notice, is given to the source. 
The Aggregate Effects of Health Insurance: Evidence from the Introduction of Medicare Amy Finkelstein

NBER Working Paper No. 11619

September 2005

JEL No. H51, I11, I18

\title{
$\underline{\text { ABSTRACT }}$
}

This paper investigates the effects of market-wide changes in health insurance by examining the single largest change in health insurance coverage in American history: the introduction of Medicare in 1965. I estimate that the impact of Medicare on hospital spending is substantially larger than what the existing evidence from individual-level changes in health insurance would have predicted. Consistent with a disproportionately larger impact of aggregate changes in health insurance, the evidence suggests that the introduction of Medicare altered the practice of medicine. For example, I find that the introduction of Medicare is associated with an increase in the rate of adoption of thennew medical technologies. A back of the envelope calculation based on the estimated impact of Medicare suggests that the overall spread of health insurance between 1950 and 1990 may be able to explain at least forty percent of the increase in real per capita health spending over this time period.

\author{
Amy Finkelstein \\ MIT Department of Economics \\ 50 Memorial Drive \\ E52-262F \\ Cambridge, MA 02142 \\ and NBER \\ afink@mit.edu
}


Over the last half-century, the dramatic rise in medical expenditures has been one of the most salient features of the health care industry. Total health care expenditures as a share of GDP have almost tripled, from about 5 percent in 1960 to about 14 percent in 2000 (CMS, 2002). Early work by Feldstein (1971, 1977) suggested that the spread of health insurance was a primary cause of the rapid rise in health spending. Such arguments prompted the undertaking of the Rand Health Insurance Experiment, one of the largest randomized, individual-level social experiments ever conducted in the United States, to investigate the impact of health insurance on health care utilization and spending (Manning et al. 1987). Its findings suggested that the responsiveness of health spending to health insurance was substantially smaller than what Feldstein $(1971,1977)$ had estimated, and consequently, that the spread of health insurance was not an important cause of the rise in health spending (Newhouse et al. 1993, Newhouse 1992). Today, the results of the Rand Experiment are generally accepted as the gold standard, and are widely used in both academic and applied contexts (Cutler and Zeckhauser 2000, Zweifel and Manning 2000).

This paper revisits this earlier debate and suggests that health insurance may have played a much larger role in the growth of health spending and the change in the practice of medical care than the findings of the Rand Experiment would suggest. The basic insight behind the paper's empirical findings is that market-wide changes in health insurance may have fundamentally different effects on the health care sector than what partial equilibrium analyses such as the Rand Experiment would suggest. Understanding the impact of market-wide changes in health insurance is crucial for analyzing the optimal design of health insurance systems, as well as evaluating the role played by the spread of health insurance in the rise in health spending.

To study the impact of market-wide changes in health insurance, I examine the impact of the introduction of Medicare in 1965, the single largest change in health insurance coverage in the United States. I use the fact that the elderly in different regions of the country had very different rates of private insurance coverage prior to Medicare to identify its effect on the hospital sector, the single largest component of health spending. I find that, in its first ten years, the introduction of Medicare was 
associated with a substantial increase in hospital utilization, employment, and capital inputs. My estimates suggest that, in its first five years, the introduction of Medicare was associated with an increase in spending that was at least four times larger than what the estimates from the Rand Health Insurance Experiment would have predicted. They also suggest that the long-term impact of Medicare on spending is likely to have been even larger than the five-year estimate.

One reason why the general-equilibrium impact of a market-wide change in health insurance may be much larger than what partial-equilibrium analysis would suggest is that market-wide changes in health insurance can fundamentally alter the nature and character of medical practice in ways that small-scale changes will not. I present additional evidence that is consistent with this explanation. For example, I find that the introduction of Medicare is associated with an increase in treatment intensity, as measured by hospital expenditures per patient day. In contrast, the results from the Rand HIE experiment famously concluded that health insurance affected care utilization on the extensive margin, but not the intensity of care conditional on utilization (Newhouse et al., 1993). I also find that the introduction of Medicare is associated with increased adoption of then-new cardiac technologies.

A back of the envelope calculation based on my estimates of the impact of Medicare suggest that the overall spread of health insurance between 1950 and 1990 may be able to explain at least 40 percent of the five-fold increase in real per capita health spending over this time period, and potentially much more. Public policy played an important role in the spread of health insurance over this period, through public health insurance programs such as Medicare and Medicaid as well as the tax subsidy to employer provided health insurance. The results therefore indirectly suggest that U.S. policy figured prominently in the substantial growth in the health care sector over the last half century.

Although these estimates suggest a larger role for health insurance in contributing to the rise in health spending than the current conventional wisdom (Newhouse, 1992), they are at the same time consistent with the consensus among health economists that technological change in the health sector is the primary cause of the rapid rise in health expenditures (see e.g. Newhouse 1992, Fuchs 1996, Cutler 2003). My findings suggest that the large impact of market-wide changes in health insurance on health spending may 
stem in part from their impact on decisions to adopt new medical technologies, as conjectured by Weisbrod (1991).

Of course, a complete picture of the impact of an aggregate change in health insurance requires an understanding not only of its impact on the health care sector - the subject of this paper - but also of its benefits to consumers. In related work, Finkelstein and McKnight (2005) explore these potential benefits and find that while the introduction of Medicare appears to have had no impact on elderly mortality in its first ten years, it did substantially reduce the right tail of out of pocket medical spending by the elderly; we estimate that this reduction in risk exposure may have produced considerable welfare gains.

The rest of the paper proceeds as follows. Section 2 describes the empirical strategy and data. Section 3 presents estimates of the effect of Medicare on hospital utilization, inputs and spending. Section 4 shows that the estimated impact of Medicare is substantially larger than what existing partial equilibrium analysis would have predicted, and presents some evidence for the likely explanations. Section 5 provides a back of the envelope calculation of what the estimates imply for the contribution of the spread of health insurance to the growth of the health care sector over the last half century. Section 6 shows that the findings are robust to a wide range of alternative specifications. The last section concludes.

\section{Studying the impact of Medicare: Approach and Data}

Medicare is currently one of the largest health insurance programs in the world, providing health insurance to 40 million people and comprising one-eighth of the federal budget and 2 percent of GDP (National Center for Health Statistics 2002, Newhouse 2002, US Congress 2000). Yet we know surprisingly little about the impact of the introduction of this major change in health care financing on the health care sector. Indeed, to my knowledge, the only existing evidence comes from a comparison of time series patterns of health expenditures before and after its introduction (Feldstein and Taylor 1977).

There are two major obstacles to any analysis of the impact of the introduction of Medicare on the health care sector: how to distinguish the impact of the national Medicare program separately from other 
co-incident secular changes, and where to find detailed, disaggregated, historical data on the health care sector. This section discusses the paper's approach to surmounting each of these hurdles.

\subsection{Identifying the impact of Medicare: geographic variation in pre-Medicare insurance coverage}

Medicare, enacted in July 1965, provides universal public health insurance for the elderly (coverage for the disabled was added in 1973). It was implemented nationwide on July 11966 . It covered both inpatient hospital expenses (Part A) and physician expenses (Part B), reimbursing for both on the basis of "reasonable costs of services". Both the set of covered services and the reimbursement structure were very generous for that time (Somers and Somers 1967, Newhouse 2002).

Prior to Medicare, public health insurance coverage was practically non existent, and meaningful private health insurance for the elderly was also relatively rare (Stevens and Stevens, 1974, United States Senate 1963, Anderson and Anderson 1967, Epstein and Murray, 1967). In the absence of insurance coverage, many of the health expenditures for the elderly were paid out of pocket either by the patient or by relatives; some health care consumption was also provided free by hospitals (Finkelstein and McKnight, 2005, Anderson and Anderson 1967 and Epstein and Murray 1967).

Medicare had an enormous impact on health insurance coverage for the elderly. Based on data from the 1963 National Health Survey (NHS), I estimate that in 1963, only 25 percent of the elderly had meaningful private hospital insurance in $1963 .{ }^{1}$ Upon the implementation of Medicare, hospital insurance coverage for the elderly rose virtually instantaneously to almost 100 percent (US Department of Health, Education and Welfare, 1969). As a result, the introduction of Medicare increased the proportion of the elderly with hospital insurance by 75 percentage points.

The impact of Medicare on elderly insurance coverage varied considerably across different areas of the country. Through a special request to the government, I obtained a version of the 1963 NHS that identifies the sub-region of the United States in which the individual is located; there are 11 possible subregions. The data indicate that the proportion of the elderly (individuals aged 65 plus) without meaningful

\footnotetext{
${ }^{1}$ For more detailed information on the 1963 National Health Survey, see National Center for Health Statistics, 1964. I am extremely grateful to Will Dow for his work in unearthing these data.
} 
private hospital insurance prior to the introduction of Medicare ranged considerably, from a low of 49 percent in New England to a high of 88 percent in the East South Central United States. In 1965, the elderly constituted 10 percent of the population, but 20 percent of hospital expenditures. ${ }^{2}$ As a result, the proportion of ex-ante hospital expenditures affected by Medicare varied across the country from about 10 percent to about 18 percent. This geographic variation allows me to identify the effect of Medicare separately from any underlying secular trends in the hospital sector. ${ }^{3}$

A key criterion for using geographic variation in insurance coverage to identify the impact of Medicare is that private insurance for the elderly was redundant of what Medicare subsequently covered. Consistent with this, Finkelstein and McKnight (2005) present evidence of a substantial crowd-out effect of Medicare's introduction on private health insurance spending. Moreover, the NHS contains data not only on whether the individual had hospital insurance, but whether this plan was a Blue Cross (BC) insurance plan. This is particularly useful since much of the private insurance held by the elderly at this time was minimalist in nature (Epstein and Murray 1967, Anderson and Anderson 1967). However, the Blues plans had among the most generous- if not the most generous - benefit coverage (Anderson et al., 1963). Perhaps even more importantly, Medicare's benefit and reimbursement structure was explicitly modeled on the existing Blue Cross and Blue Shield health insurance system (Ball, 1995, Newhouse 2002, Stevens and Stevens 1974, Stevens 1999). Thus the proportion of the elderly population with a Blue Plan provides a very good measure of the proportion of the elderly who had Medicare-equivalent coverage prior to Medicare. All of the statistics above on private hospital insurance coverage are based on coverage by Blue Cross hospital insurance.

Figure 1 and Table 1 show the geographic distribution of the proportion of the elderly without Blue Cross hospital insurance coverage in 1963 across the 11 sub-regions; such insurance would cover the

\footnotetext{
${ }^{2}$ Population estimates come from interpolating the 1960 and 1970 census estimates. The elderly's share of hospital expenditures is calculated using the 1963 Survey of Health Service Utilization and Expenditures.

${ }^{3}$ Although variation across areas in the percent of the population that is elderly might seem a natural choice as well, in practice this provides very little additional variation. As a result, in Section 6, I show that the basic results are not affected by using this additional variation.
} 
hospital expenses subsequently covered by Medicare Part A. ${ }^{4}$ Broadly speaking, insurance coverage is higher in the North East and North, and lower in the South and West. Table 1 also indicates that the geographic pattern in the percentage of individuals without any hospital insurance is similar to that for $\mathrm{BC}$ hospital insurance (although the national mean is substantially lower); below I show that the estimated impact of Medicare is robust to using either measure of hospital insurance. The geographic pattern in BC hospital insurance coverage appears extremely stable over time. ${ }^{5}$

The empirical strategy is to compare hospital outcomes before and after Medicare in areas of the country where Medicare had a larger effect on the percent of the elderly with health insurance to areas where it had less of an effect. Since this approach will not capture any effect of Medicare on the previously-insured that operates via the income effect, it may underestimate of the full impact of Medicare.

Of course, private insurance rates prior to Medicare are not randomly assigned. Data from the 1960 census indicate that variation in socio-economic status can explain a substantial share of the variation in insurance coverage across sub-regions, and that socio-economic status and insurance coverage are highly positively correlated. Areas that differ in their socio-economic status are also likely to differ in terms of their desired level of medical spending, or growth in medical spending. The empirical approach is therefore to discern the effect of Medicare by looking at whether there is a break in any pre-existing differences in the level or trend in these outcomes around the time of Medicare's introduction in 1966.

\subsection{Data: The American Hospital Association Annual Survey}

I study the impact of Medicare on the hospital sector, which was the single largest component of health spending at the time of Medicare's introduction, as well as the single largest component of the subsequent growth in health spending (National Center for Health Statistics, 2002). For the analysis, I use

\footnotetext{
${ }^{4}$ The data also contain information on whether the individual has Blue Shield surgical insurance (which is subsequently covered by Medicare Part B). Since coverage patterns for hospital and surgical insurance are virtually identical, and the analysis in this paper is on the impact of Medicare on the hospital sector, I use the hospital insurance coverage rates in the analysis.

${ }^{5}$ The correlation across the four census regions of the percent of the elderly without BC hospital insurance in the 1959 and 1963 NHS is 0.99 (see National Center for Health Statistics 1960 for aggregate statistics on health insurance by census region in the 1959 data).
} 
26 years of hospital-level data from the annual surveys of the American Hospital Association (AHA) for every AHA-registered hospital in the U.S. These historical data, which I found in hard-copy in the annual August issues of Hospitals: The Journal of the American Hospital Association, cover the years from 1948 to 1975 (with the exception of 1954). The AHA data from the 1980s and later are widely used in studies of the hospital sector (e.g. Baker and Phibbs (2002), Cutler and Sheiner (1998), Duggan (2000)).

However, the historical data have been largely ignored. Appendix A provides a detailed description of the data quality.

I limit the sample to the approximately three-quarters of hospitals that are private hospitals; about two-thirds of these private hospitals are non-profit. The sample therefore consists of about 4,500 hospitals per year. I exclude the public hospitals from the main analysis because the identification strategy is illsuited to examining the effect of Medicare on public hospitals. Public hospitals serve a predominantly (or perhaps exclusively) poor and uninsured population, regardless of the overall rate of private insurance coverage in the sub-region (Stevens 1999). I show below in Section 6, however, that the results are robust to including the public hospitals. ${ }^{6}$

The main analysis of the paper examines the impact of Medicare on six hospital outcomes: total expenditures, payroll expenditures, employment, beds (a common proxy for the hospital capital stock), admissions and number of patient days. Utilization and bed data are exclusive of newborns. All expenditure variables in the paper are converted to 1960 dollars using the CPI-U. Note that hospital expenditures do not include any hospital markup; this would be captured by hospital revenue, which is not reported. Also note that employment and payroll expenditures tend not include physicians since most are not employed directly by the hospital. Appendix A provides a more detailed description of these variables.

\footnotetext{
${ }^{6}$ The non-random sorting of insured individuals across hospital types also suggests that the estimated effects on private hospitals may be biased down as well. I would like to measure the percent of potential patients without private insurance in private hospitals in a given area, but instead observe the percent of the population without private insurance in a given area; since the public hospitals attract almost entirely patients without insurance, the variation in my observed measure may be greater than the variation in the true measure and thus my estimates may be biased down.
} 
Figure 2 shows the national time series patterns for each of these variables. The figure also shows a quadratic fitted to the pre period data (1965 and earlier). All of the variables are increasing over the entire period of the data. Most variables show increases after 1965 relative to the pre-existing trends. Of course, extrapolating off of the time series is potentially problematic. The mid-1960s were a period of great social change, including other important pieces of domestic legislation. The national price controls imposed in 1971 through 1974 are also likely to confound any time series analysis.

Table 2 provides summary statistics for all the outcome variables used in the study. It reports the hospital mean of the outcome variables in the period immediately prior to the introduction of Medicare (1962-1964). It also reports the means for 1962-1964 separately for hospitals in the North and NorthEast (where insurance coverage was comparatively high prior to Medicare) and for hospitals in the South and West (where insurance coverage was comparatively low prior to Medicare). Not surprisingly, the means are consistently higher in areas with a higher insurance rate prior to Medicare. Indeed, given that below I will show an effect of Medicare on almost all of these outcomes, it would be surprising if the levels were same in the pre-period when insurance rates were so different.

\section{The Impact of Medicare on Hospital Utilization, Inputs and Spending}

\subsection{Econometric model}

The empirical strategy is to compare changes in hospital-level outcomes in regions of the country where Medicare had a larger effect on the percentage of the elderly with health insurance to areas where it had less of an effect. The basic estimating equation is:

$$
\log \left(y_{i j t}\right)=\alpha_{j} * \mathbf{1}\left(\text { county }_{j}\right)+\delta_{t} * \mathbf{1}\left(\text { Year }_{t}\right)+\sum_{t=1948}^{t=1975} \lambda_{t}\left(\text { Mcareimpact }_{z}\right) * \mathbf{1}\left(\text { Year }_{t}\right)+X_{s t} \beta+\varepsilon_{i j t}
$$

The dependent variable is the $\log$ of outcome $y$ in hospital $i$ in county $j$ and year $t$. I estimate the equation in logs because the hospitals vary considerably in size, and therefore constraining the outcomes to all grow according to a series of common (level) year fixed effects seems inappropriate. $\mathbf{1}\left(\right.$ County $\left._{j}\right)$ are a series of county fixed effects that control for any fixed differences across counties in the outcome of 
interest. $\mathbf{1}\left(\right.$ Year $\left._{t}\right)$ are a series of year fixed effects that control flexibly for any common secular year effects for the whole nation. Mcareimpact $t_{\mathrm{z}}$ measures the percentage point increase in insurance coverage in subregion $z$ associated with the introduction of Medicare. In the baseline specification I define Mcareimpact $_{\mathrm{z}}$ as the percentage of the elderly population in subregion $z$ without private Blue Cross hospital insurance in 1963; this ranges from a high of 0.88 in the East South Central United States to a low of 0.49 in New England (see Table 1).

The key variables of interest are the interactions of the year fixed effects with the Mcareimpact variable $\left(\left(\right.\right.$ Mcareimpact $\left._{z}\right) * \mathbf{1}\left(\right.$ Year $\left.\left._{t}\right)\right)$. The pattern of coefficients on these variables - the $\lambda_{t}{ }^{\prime} s-$ shows the flexibly estimated pattern over time in the dependent variable in areas where Medicare had a larger impact on insurance coverage relative to areas where it had a smaller impact. The change in the trend of these $\lambda_{t}{ }^{\prime} s$ before and after the introduction of Medicare can therefore provide an estimate of Medicare's impact on the dependent variable. Crucially, equation (1) does not privilege 1965 relative to other years for when any changes might occur; this allows the data to show where changes in the time pattern - if any - actually occur and to gauge whether Medicare may plausibly have played a role. ${ }^{7}$

To account for possible correlation across hospitals over time within areas, I allow for an arbitrary variance-covariance matrix within each state. I verified that the p-values are very similar if instead I implement the randomized inference procedure described by Bertrand et al. (2004). Clustering at the subregion produces substantially smaller p-values, although with only 11 sub-regions the desirable asymptotic properties of clustering may not obtain.

The empirical approach is to look for a break in any pre-existing differences in the level or trend in these hospital outcomes across areas that were differentially affected by Medicare around the time of Medicare's introduction in 1966. The identifying (or, counterfactual) assumption is that absent Medicare, any pre-period differences would have continued. I use the almost 20 years of data prior to the

\footnotetext{
${ }^{7}$ In the sensitivity analysis in Section 6, I show that the results are robust to a variety of alternative ways of parameterizing the impact of Medicare, such as using an indicator variable for whether the area has more than a certain percent of the elderly without private insurance, rather than requiring the percent without insurance to enter linearly, as in the baseline specification.
} 
introduction of Medicare to provide support for this identifying assumption (see Section 6). In addition, to alleviate concerns that other things might also have been changing differentially over time across different areas of the country, equation (1) also includes a series of time-varying state-level covariates $\left(X_{s t}\right)$.

A potentially important confounding factor is the impact of Medicaid. Like Medicare, Medicaid was also enacted in 1965; it provides health insurance to some of the indigent. In the time period under examination, it was a considerably smaller program than Medicare (National Center for Health Statistics, 2002). Because the timing of Medicaid implementation - unlike Medicare - was left up to the individual states, I can separately control for any impact of Medicaid; all but one state enacted its Medicaid program between 1966 and 1972 (Gruber, forthcoming). I therefore include as the time-varying state-level covariates $\left(X_{s t}\right)$ in the baseline specification, a series of eight indicator variables for the number of years since (or before) the implementation of a Medicaid program in state $s$. In practice, the estimated effects of Medicare are not sensitive to including these controls for Medicaid implementation. ${ }^{8}$ In the sensitivity analysis in Section 6 I show the results are robust to adding other time-varying state-level covariates as well.

\subsection{Results}

The core empirical findings are readily apparent in Figure 3 which shows the $\lambda_{t}{ }^{\prime} s$ from estimating equation (1) for six different dependent variables: admissions and patient days (i.e. hospital utilization), employment and beds (i.e. hospital inputs) and payroll expenditures and total expenditures (i.e. hospital expenditures). These $\lambda_{t}{ }^{\prime} s$ are the coefficients on each of the year effects interacted with the impact of Medicare on insurance coverage in the sub-region. The pattern of the $\lambda_{t}{ }^{\prime} s$ over time therefore identify changes in the dependent variable in areas in which Medicare had a larger impact on insurance coverage relative to areas in which Medicare had a smaller impact. Since the coefficients identify only changes in

\footnotetext{
${ }^{8}$ Although in principle, estimates of equation (1) could shed light on the impact of Medicaid, in practice, the results suggest that the timing of state implementation of Medicaid is not random with respect to hospital outcomes, and analysis does not yield stable estimates of the impact of Medicaid.
} 
the dependent variable relative to the omitted year (1965), I normalize $\lambda_{t}$ in 1965 to the difference in the mean of the dependent variable in 1962-1964 between the South and the West (where Medicare had a larger impact) and the North and Northeast (where Medicare had a smaller impact). The dots indicate the 95 percent confidence interval for each coefficient. ${ }^{9}$ A vertical line demarcates 1965 , the year in which Medicare is enacted. ${ }^{10}$

Consider first the results for hospital admissions (the upper-left graph in Figure 3). There is a general downward trend over time in the $\lambda_{t}{ }^{\prime} s$ up through 1965 . This indicates that, prior to 1965 , hospital admissions are not growing as fast in low insurance areas relative to high insurance areas; this is not surprising, given the socio-economic difference across the areas discussed above. However, Figure 3 indicates a dramatic reversal in this pattern after 1965 (the year in which Medicare is enacted). After 1965, admissions start to grow faster in the areas where Medicare's introduction had a larger impact on insurance (i.e. previously low insurance areas) relative to areas where it had less of an impact.

The other hospital outcomes examined in Figure 3 show the same basic results. Hospital outcomes are growing less quickly in more affected areas (i.e. lower insurance coverage areas) relative to less affected areas prior to Medicare's introduction. The introduction of Medicare in 1965 is followed by a dramatic reversal of this pattern for all outcomes; hospital outcomes then begin to grow more quickly in areas more affected by Medicare relative to less affected areas.

Of course, there is some variation across outcomes in how sharp the change is with the introduction of Medicare. The results for beds are particularly dramatic. Patient days are an exception to the general pre-period trend; they are changing at a relatively similar rate in the different sub-regions prior to Medicare. Even still, there is evidence of a relative increase in patient days in more affected areas relative to less affected areas after Medicare's introduction. The results for payroll and total expenses follow the

\footnotetext{
${ }^{9}$ Since 1965 is the reference year, and the coefficients are on the interaction of year fixed effects with Mcareimpact, the confidence intervals naturally tend to increase as we go further from 1965 in either direction.

${ }^{10}$ Data from year $t$ are from the survey period October $(\mathrm{t}-1)$ to September $(\mathrm{t})$. Since Medicare was enacted in July 1965 and implemented in July 1966, the year 1965 (i.e. Oct 1964 to Sept 1965) is treated as the year prior to Medicare. Any effects detected in 1966 (i.e. Oct 1965 to Sept 1966) may be anticipation or actual effects.
} 
same basic pattern as the other outcomes, albeit with more noise, which may reflect the greater noise in the expenditure measures (see Appendix A). In Section 6, I examine more formally whether the data provide evidence of breaks in trends in earlier periods and find no compelling evidence that they do.

I perform a variety of statistical tests of the coefficients graphed in Figure 3. Motivated by the graphical results, all of these tests estimate the n-year change in $\lambda_{t}$ after the introduction of Medicare relative to the n-year change in $\lambda_{t}$ before the introduction of Medicare. For example, the impact of Medicare in the first five years is calculated as follows:

$\Delta 5 \equiv\left(\lambda_{1970}-\lambda_{1965}\right)-\left(\lambda_{1965}-\lambda_{1960}\right)$

$\Delta 5$ thus denotes the five-year change in the hospital outcome after the introduction of Medicare relative to the five years prior to the introduction of Medicare for areas in which Medicare had a greater impact on insurance coverage relative to areas where it had a smaller impact.

The first three rows of Table 3 report the estimates for the two-year, five-year and ten-year change in the outcome, respectively. P-values are reported in parentheses below each estimate. Each column shows the result for a different dependent variable. The results provide statistical confirmation of the visual evidence in Figure 3; they uniformly indicate that the introduction of Medicare is associated with a substantial and statistically significant increase in all of the dependent variables.

Because the reference (or pre-) period changes with the two-year five-year and ten-year tests, comparisons across the test should not be interpreted as a different effect at different time intervals. To compare the effects in different time intervals, the fourth row of Table 3 repeats the five-year test for the second five years comparing the period 1975 to 1970 to the reference period 1965 to 1960; it thus uses the same reference period as he first five year test in row 2 (which compares the period 1970 to 1965 to that of 1965 to 1960). The results indicate that Medicare is associated with a further statistically significant increase in five of the six outcomes (all but patient days) in the second five year period.

In results not reported, I further explored the nature of the providers' response to Medicare. I find that, at most of the time horizons examined in Table 3, Medicare is associated with a moderate (but not 
statistically significant) decline in average length of stay (measured by patient days / admissions); this may be because the marginal patient admitted as a result of Medicare is less sick than the average preMedicare patient. I also find that in its first two years Medicare is associated with a statistically significant increase in occupancy rates (measured by patient days / beds), followed by a statistically significant decline in occupancy rates in its second five years. The initial increase presumably reflects a lag in bed construction; the subsequent decline may be due to Medicare's original generous capital depreciation allowances which created incentives for inefficient expansion (Somers and Somers 1967, United States Senate 1970), or it may have been an unintended consequence of poor forecasting of the increase in demand. I also find evidence that at most of the time horizons examined in Table 3, the introduction of Medicare is associated with an increase in hospital wages (as measured by payroll expenses / employment). This is somewhat surprising since the labor supply of nurses, technicians, and custodial staff is presumably relatively elastic. One possibility is that the increase in wages reflects an increase in the marginal product of the hospital employees - perhaps due to the adoption of new technologies or to hiring of higher quality labor. Another possibility is that labor shared in some of the rents that hospitals received from the introduction of Medicare.

Row 5 of Table 3 reports the results from weighted estimation of equation (1) in which each hospital is weighted by its average size (number of beds) prior to Medicare (i.e. in 1963 and 1964). ${ }^{11}$ To conserve space I report results from the five-year estimates only; the time pattern of the other estimates (not shown) is similar to that in the unweighted sample. The weighted analysis produces smaller estimates for hospital utilization and spending, but larger estimates for hospital inputs (beds and employment). Some of these differences are substantial. In particular, the impact of Medicare on admissions and total spending is about half as large in the weighted analysis than in the unweighted analysis.

\footnotetext{
${ }^{11}$ This analysis requires linking hospitals across years. As there are no hospital identifiers in the hard copy data, I use the hospital name and location (county and state) to link hospitals across years. In cases of ambiguity, I erred on the conservative side of not creating false links; as a result, I could link only 80 to 90 percent of the hospitals (depending on the outcome and hence the years of analysis) to their counterpart in 1963 and 1964. I verified however that differences between the weighted and unweighted estimates almost entirely reflect the effect of weighting, rather than sample definition.
} 
The correct interpretation of these differences between the weighted and unweighted specifications is not clear. They may reflect heterogeneity across hospital sizes in the treatment effect. However, they may also reflect unobserved heterogeneity across hospital sizes in the treatment size, as I do not have data on insurance coverage rates prior to Medicare for patients at hospitals of different size. To the extent that it reflects genuine heterogeneity in the treatment effect, the weighted estimate provides a more accurate estimate of the impact of Medicare on national spending. ${ }^{12}$ To be conservative, I therefore use the weighted analysis for my central estimates, since they suggest a substantially smaller impact of Medicare on total spending and admissions.

To translate the estimates in Table 3 into the implied national impact of Medicare, we must multiply them by 0.75 , since nationwide, Medicare increased the proportion of the elderly with insurance coverage by 75 percentage points. The smaller results from the weighted analysis therefore imply that the introduction of Medicare is associated with an increase in admissions of 29 percentage points (34 percent) and in total spending of 21 percentage points ( 23 percent) in its first five years. The results from the unweighted analysis imply that the introduction of Medicare is associated with an increase in admissions between 1965 and 1970 of 63 percent and in total spending of 49 percent. In both the unweighted (see Table 3 row 4) and the weighted analysis (not shown), these increases continue in the second five year period, suggesting that the long-run impact of Medicare is even larger. ${ }^{13}$

These estimates speak to the effect of Medicare on total admissions and spending for all ages. Prior to Medicare, the elderly constituted 20 percent of total hospital spending. As a result, if the impact of Medicare were limited to the elderly, the smaller estimates from the weighted analysis imply that Medicare would have increased the elderly's hospital spending by 115 percent and the elderly's hospital admissions by 170 percent after it had been in effect for five years. I discuss evidence below, however,

\footnotetext{
${ }^{12}$ If Medicare is associated with a change in the number of hospitals this would further complicate using the results in Table 3 to infer the nationwide impact of Medicare. However, I investigated this potential effect and did not find evidence of an impact of Medicare on hospital numbers.

${ }^{13}$ Interestingly, the simple time series comparison in Figure 2 of the growth of the hospital sector since 1965 relative to a pre-existing quadratic trend yields quite comparable estimates on spending, suggesting that Medicare is associated with a 27 percent increase in hospital spending by 1970. However, the time series evidence shows no impact of an effect of Medicare on hospital admissions.
} 
that suggests that the introduction of Medicare may have had spillover effects on the treatment of the nonelderly, and thus its impact on health spending may not have been limited to the elderly.

Data from the National Health Expenditure Accounts indicate that real hospital expenditures grew by 63 percent between 1965 and 1970, compared to only 41 percent over the previous five years. The larger estimates from the unweighted analysis therefore suggest that the introduction of Medicare can explain about three-quarters of the growth in hospital spending between 1965 and 1970. The smaller estimates from the weighted analysis imply that Medicare can account for about one-third of the growth in hospital spending over this five year period or all of the above-average growth relative to the previous five years.

\section{Partial Equilibrium vs. General Equilibrium Effects of Health Insurance}

\subsection{Comparison to the Rand HIE estimates}

The estimated impact of Medicare on the hospital sector is substantially larger than what would have been predicted based on existing evidence from the small-scale changes in health insurance in the Rand HIE. If we apply the estimates from the Rand experiment to predicting the impact of Medicare, they imply that Medicare would increase total hospital spending (for all ages) by about 5.6 percent; Appendix B provides the details behind this calculation. This estimate is about one-fourth the magnitude of the 23 percent effect of Medicare on health spending in its first five years that I estimated above in the weighted analysis, and about one-tenth the magnitude of the 49 percent increase in health spending from the unweighted analysis. As discussed, there is evidence that the longer-term impact of Medicare on health spending is likely to have been even larger than the five-year estimates.

Several aspects of the design of the Rand experiment facilitate the comparison of my estimates with what the Rand estimates predict the impact of Medicare would have been. The Rand experiment took place only shortly after the introduction of Medicare (it was conducted from 1974 to 1982), so that the time period of the estimates is similar. Both provided hospital insurance for free to the original beneficiaries, so that both estimates incorporate this positive income effect on health spending. ${ }^{14}$ The

\footnotetext{
${ }^{14}$ Medicare's hospital insurance was financed with a payroll tax on workers, to which the first generation of elderly beneficiaries therefore did not contribute.
} 
experiment provides estimates of the effect of moving from no insurance policy to a policy similar to the original Medicare policy (see Appendix B for details). It also provides estimates separately for hospital spending. Finally, the Rand experiment specifically investigated the impact of shorter versus longer time changes in health insurance and found no differences, suggesting that the expected permanence of Medicare relative to the Rand experiment is unlikely to be an important factor. However, the Rand experiment excluded individuals age 62 and over, while Medicare covers individuals age 65 and over. It seems doubtful that differences in the spending response of the elderly and non-elderly alone could be large enough to explain the over four-fold higher estimated impact of Medicare on hospital spending. Indeed, a priori, it is not clear whether to expect a higher spending response to price subsidies by the elderly (for example, because they tend to be poorer than the non-elderly), or a lower response (for example, because their health problems are likely to be more severe.)

As discussed in Appendix B, it is more difficult to translate the Rand estimates into the implied increase in admissions that would be associated with the introduction of Medicare. Nevertheless, the available evidence suggests that the admissions response estimated above is also substantially larger than what would be predicted by the Rand estimates.

Theoretically, there are reasons to have expected the impact of market-wide changes in health insurance to be disproportionately smaller than that of an individual's change in health insurance. For example, models of physician-induced demand suggest that while the substitution effect of health insurance encourages increased physician treatment intensity, the income effect has the opposite tendency. Because the income effect will loom larger for market-wide changes in insurance coverage relative to individual changes, the impact of market-wide changes in health insurance may be disproportionately smaller than the impact of individual changes (McGuire and Pauly, 1991).

There are two classes of theoretical explanations for the empirical finding that market-wide changes in health insurance appear to have a disproportionately larger impact on the health care sector than what evidence from small-scale changes in health insurance would suggest: the "fixed costs" and "spillovers" 
hypotheses. ${ }^{15}$ The "fixed costs" hypothesis is that aggregate changes in health insurance may sufficiently change the nature and magnitude of the market demand for health care that they alter the incentives for hospitals or physicians to incur the fixed costs of adopting new practice styles. For example, market-wide changes in health insurance may expand aggregate demand to the point where it is now possible to cover the fixed costs of providing a technology for which demand was not previously sufficiently high.

The "spillovers" hypothesis is that the typical insurance coverage in a community determines a community standard of care that affects the treatment of all patients in the community. As a result, changes in insurance coverage for a subset of patients can, by affecting the average insurance in the community, have spillover effects onto a hospital's treatment of other patients whose insurance coverage has not changed. Although the original exploration of this hypothesis by Newhouse and Marquis (1978) found little support for it, several subsequent studies have found that variation in the typical insurance coverage in a physician's practice or market area affects treatment intensity and health spending for other individuals (Glied and Graff Zivin 2002, Baker 1997, Baker and Shankarkumar 1998).

The spillovers and fixed costs hypothesis may be complementary, and therefore not necessarily separable in an accounting sense. For example, if Medicare induces a hospital to incur the fixed cost of adopting a new technology, the new technology, once adopted, may also be used on non-elderly individuals. However, spillovers may also result for reasons other than the joint nature of hospital production, such as medical ethics, fears of malpractice liability, or simply hospital income effects. While the fixed costs hypothesis entails fundamental non-linearities in the impact of health insurance on health spending, the spillovers hypothesis, by contrast, can operate even if the typical community health insurance has a linear impact on health spending (although there may also be important non-linearities). The rest of this section provides suggestive empirical evidence for each hypothesis. ${ }^{16}$

\subsection{Indirect evidence for the "fixed costs" hypothesis: change in treatment intensity}

\footnotetext{
${ }^{15}$ Another possibility is that a market-wide increase in health insurance may allow hospitals to increase the mark up that they charge for their services. While such an effect may well be present, it will not captured in my estimates which are of the effect of Medicare on hospital expenses, not hospital revenues. See Appendix A for more detail. ${ }^{16}$ Although this discussion is couched in terms of the disproportionately larger effects of Medicare on spending, both hypotheses may also help explain the disproportionately larger impact of Medicare on hospital utilization.
} 
Table 4 presents estimates that suggest that - after its first five years - Medicare is associated with an increased in hospital expenditures per patient day, whether measured as payroll expenditures or total expenditures. The increase in treatment intensity appears to reflect an increase in both employment and beds per patient day, although only the increase in beds per patient day is statistically significant. Given the large increase in admissions associated with Medicare's introduction (see Table 3), it is likely that the marginal admission is substantially less sick than the average pre-Medicare admit. As a result, the actual increase in treatment intensity - measured on a risk adjusted basis - is likely to be considerably larger than what has been measured here.

The impact of Medicare on spending per patient day is particularly striking in light of the notable finding of the Rand HIE that increases in an individual's health insurance affect his probability of care utilization, but not the amount of spending conditional on utilization (Newhouse et al., 1993). This disparity is consistent with market-wide changes in health insurance - such as those induced by Medicare - having effects on practice patterns that small-scale changes do not. It is thus indirect evidence for the "fixed costs" hypothesis.

\subsection{Direct evidence for the "fixed costs" hypothesis: the impact of Medicare on technology adoption}

Since medical technologies are an important component of hospital costs, any impact of Medicare on the adoption of new technologies may play a large role in explaining why market-wide changes in health insurance appear to have disproportionately larger effects than individual-level changes. An impact of Medicare on technology adoption is also particularly well-suited for supporting the "fixed costs" hypothesis since this theory is one of discrete changes in practice style, not in the marginal addition of lumpy goods. ${ }^{17}$

Theoretically, however, it is not obvious whether Medicare would have an effect on technology adoption decisions. By lowering the marginal cost of technology use, fee for service health insurance

\footnotetext{
${ }^{17}$ By contrast, the above evidence of a substantial impact of Medicare on the construction of new hospital beds is less obviously a contributor to the larger aggregate impact of health insurance. Assuming that hospitals price based on average costs, an insurance-induced increase in hospital beds will only disproportionately increase spending if the increase in supply itself generates its own increase in demand, or if hospitals are operating on the increasing part of their average cost curve.
} 
might induce technology adoption (Weisbrod, 1991). However, it is also possible that the income effect for physicians of an aggregate increase in health insurance might slow the adoption of new medical technologies (McGuire and Pauly, 1991). Or, physicians' training may cause them to act according to a "technological imperative" to adopt the latest new medical technology regardless of the insurance environment; indeed, American hospitals' exceptionalism in the eagerness to adopt new technologies was already well-noted in the decades prior to introduction of Medicare (Stevens, 1999).

The existing empirical evidence indicates that areas with higher managed care penetration exhibit slower rates of diffusion of new technologies (Cutler and Sheiner 1998, Baker 2001, Baker and Phibbs 2002). However, it is unclear whether this is due to the financial incentives per se that are embodied in managed care, or to the direct oversight and regulation of technology adoption that is part and parcel of the managed care approach (Glied 2000, Baker and Phibbs 2002).

I focus on the impact of Medicare on whether hospitals adopt the then-new, high cost cardiac technologies. New cardiac technologies have played an important role in both the rise of health spending and the improvement in life expectancy over the last several decades (Cutler, 2003). Moreover, if Medicare does have an effect on technology adoption, it is especially likely to show up in the adoption of cardiac technologies which are used disproportionately for the elderly. There are no such technologies in the AHA data prior to Medicare; however, two important new cardiac technologies entered the data after 1965: the open heart surgery facility and the cardiac intensive care unit (CICU). ${ }^{18}$

To assess whether Medicare had an impact on hospitals' adoption of these technologies, I examine the geographic patterns of hospital adoption of these technologies across the various sub-regions in which insurance coverage was more or less affected by the introduction of Medicare. I employ two different control strategies to proxy for what this geographic adoption pattern would have looked like in the absence of Medicare. Both use technologies that are at a similar point in their nationwide diffusion to the

\footnotetext{
18 The AHA data contain only binary information on whether the hospital has a given technology. I will therefore not capture any impact of Medicare on other margins such as how many machines the hospital has, how often they are used, or when they were last upgraded. Despite these limitations, the AHA technology data have been widely used to study the impact of managed care on hospital technology adoption in the 1980s and 1990s (e.g. Cutler and Sheiner 1998, Baker 2001, Baker and Phibbs, 2002).
} 
cardiac technologies but are less likely to be affected by Medicare. One control strategy studies the geographic diffusion pattern of technologies that reached the diffusion level of the cardiac technologies prior to Medicare's introduction. The other control strategy studies the geographic diffusion pattern of technologies that diffused to roughly the same level as the cardiac technologies in the post-Medicare period, but whose patient base is heavily skewed away from Medicare patients.

Evidence that the geographic diffusion pattern of the cardiac technologies is more skewed toward areas with a larger impact of Medicare on insurance coverage than the geographic pattern for the control technologies is evidence against the null hypothesis that Medicare had no effect on the adoption of these new cardiac technologies. However, the analysis is not well suited to gauging the magnitude of any impact of Medicare on technology adoption, since it conditions on technologies having reached a given diffusion rate nationwide, and therefore does not pick up any impact of Medicare on the timing at which this nationwide diffusion rate is reached. ${ }^{19}$

I begin with an analysis of the impact of Medicare on the adoption of the open heart surgery facility. In 1975, 10 percent of hospitals in the data had this technology. For one set of controls, I use four other high-tech, costly technologies that had reached the same diffusion point prior to Medicare: the postoperative recovery room (which reached the 10 percent diffusion level in 1951), the electroencephalograph (EEG) (1953), the diagnostic radioactive isotope therapy (1955) and the Intensive Care Unit (ICU) (1958). ${ }^{20}$ For the other set of controls I use two technologies that are at a similar national diffusion rate to open heart surgery in the immediate post-Medicare period but that were much less likely to have their use reimbursed by Medicare: renal dialysis inpatient facilities and renal dialysis outpatient facilities. Renal dialysis is used on patients with end stage renal disease (ESRD). Prior to the 1973 - in

\footnotetext{
${ }^{19}$ An alternative approach is to examine the impact of Medicare on the subsequent diffusion of technologies that were already in the data prior to 1965 (such as the diagnostic radioactive isotope, the postoperative recovery room, the EEG, or the intensive care unit) using the hazard model approach of Baker and Phibbs (2002). The results from such analysis are quite sensitive to specification and do not provide compelling evidence that Medicare had an effect on the diffusion of these technologies. One reason may be that unlike the cardiac technologies, these technologies were not disproportionately used by the elderly (see e.g. Russell 1979) and therefore the incentive effects of Medicare on their adoption may have been weak.

${ }^{20}$ Russell and Burke (1975), Russell (1977) and Russell (1979) provide detailed descriptions of these technologies.
} 
which Medicare began covering patients with ESRD regardless of their age - virtually all patients with ESRD were under 65 and therefore not covered by Medicare (Eggers, 2000). ${ }^{21}$

Table 5 shows the results. The left-hand panel shows the coefficient $\lambda$ on Mcareimpact from estimating the following equation separately for open heart surgery and for each control technology:

Newtech $_{i s}=\lambda *$ Mcareimpact $_{z}+X_{s} \beta+\varepsilon_{i s}$

Newtech is an indicator variable for whether hospital $i$ in state $s$ has acquired the new technology in the year of analysis. Mcareimpact $_{\mathrm{z}}$ measures the increase in insurance coverage in subregion $z$ associated with the introduction of Medicare. $\mathrm{X}_{\mathrm{s}}$ controls for state-level socio-economic conditions (specifically real per capita state income, state infant mortality rate, the rate of violent crime and state population). The controls for state-level characteristics which vary over time (and hence with the year of analysis) may help control for the fact that other factors - besides Medicare - may have changed before and after Medicare and may affect the geographic pattern of technology adoption. I report results from probit analysis of equation (3) with and without the covariate controls.

The first column of Table 5 indicates that hospitals in areas where Medicare had more of an impact on insurance coverage were 6 to 7 percentage points more likely to have adopted an open heart surgery facility by 1975 than areas in which Medicare had less of an impact. By contrast, columns 2 through 7 indicate that when the control technologies had diffused to about 10 percent nationwide, areas in which Medicare had more of an impact on insurance coverage were 3 to 28 percentage points less likely to have adopted each of these new technologies than areas in which Medicare had less of an impact. ${ }^{22}$

The right hand panel of Table 5 shows the results from the difference-in-differences analysis:

$$
\text { Newtech }_{i s t}=\alpha \text { TREAT }_{i}+\delta \text { Mcareimpact }_{z}+\lambda\left(\text { Mcareimpact }_{z} * \text { TREAT }_{i}\right)+X_{s t} \beta+\varepsilon_{i s t}
$$

\footnotetext{
${ }^{21}$ Another obvious choice for non-Medicare intensive control technologies would be a new technology used for infants, such as the neo-natal intensive care unit studied by Baker and Phibbs (2002). Unfortunately, no such technologies are in the data during the time period I am examining.

${ }^{22}$ In results not reported, I confirmed that these results are not sensitive to changing the year of analysis by a few years on either side, subject to data availability. Renal dialysis inpatient first comes in in 1968 at 13 percent therefore I use the first year. Renal dialysis outpatient reaches 10 percent in 1973.
} 
TREAT is an indicator variable for whether technology $i$ is open heart surgery. The key variable of interest is Mcareimpact*TREAT.

The difference-in-differences analysis using the four older technologies as controls (column 8) indicate that the geographic adoption pattern of open heart surgery facilities is statistically significantly more skewed toward areas more affected by Medicare than the geographic adoption patterns of these older technologies. The assumption behind this analysis is that absent Medicare, the differential adoption of cardiac technologies across areas of the country would have looked similar to the differential adoption of older technologies across areas of the country prior to Medicare. To the extent that there are substantial technology-specific idiosyncrasies in the geographic adoption pattern or that the geographic adoption pattern would have changed substantially over time even absent the introduction of Medicare, the validity of the identifying assumption is suspect. Some supportive evidence for the identifying assumption comes from evidence of pronounced stability across time and across very different technologies in the geographic pattern of who are the "early innovators." In particular, Skinner and Staiger (2005) find a remarkable consistency in the states who were early adopters of $\beta$-Blockers in 2001 and those who were early adopters of hybrid corn in the 1930s and 1940s.

The difference-in-difference analysis using the two renal dialysis technologies as controls (column 9) also provides evidence against the null hypothesis that Medicare had no impact on cardiac technology adoption. An advantage of this strategy is that the control technologies are examined at essentially the same time period as the cardiac technologies, reducing concerns that the analysis is confounding the impact of Medicare with other secular time trends. The disadvantage of this strategy is that faced with more resources on average, hospitals may choose to spend some of it on new technologies, even if these new technologies have not become much more profitable at the margin. Such spillover effects will bias the estimates against finding an impact of Medicare on technology adoption. Consistent with such bias, the point estimates from the difference-in-difference analysis are somewhat larger when the older technologies are used as a control group than when the dialysis technologies are. 
Table 6 shows the analogous analysis of the impact of Medicare on the cardiac intensive care unit, which first appears in the data in 1969 with a diffusion rate of 41 percent. ${ }^{23}$ I compare the geographic pattern of adoption of the CICU in 1969 to the geographic pattern of adoption of two other forms of intensive care. One, the postoperative recovery room, had diffused to 41 percent prior to Medicare in 1958. The other, the general intensive care unit, was only slightly more diffused than the cardiac intensive care unit in 1969 (48 percent vs. 41 percent) but was not as concentrated in Medicare patients. Once again, the results are evidence against the null hypothesis that Medicare had no effect on the diffusion of the CICU. Again too, the difference-in-difference estimates are smaller when a less elderly-specific technology in the post-Medicare period is used as the comparison group (column 5)) than when a technology in the pre-Medicare period is used (column 4), which is consistent with Medicare having some spillover effects on general technologies.

\subsection{Indirect evidence of spillovers}

If health insurance spillovers are quantitatively important, estimates of the impact of an individual's health insurance on health spending could produce considerably downward biased estimates of the aggregate impact of health insurance on health spending. One reason is that the nature of most empirical analyses of the impact of an individual's health insurance is to use other individuals in the same market with different health insurance as a comparison group; such analysis nets out any spillover effect. Even with an empirical design that avoids this problem, it is unlikely that spillovers would be captured in a study of the impact of an individual's health insurance on health spending; the marginal impact of one's own health insurance on the typical health insurance in the community is sufficiently small that even a large spillover effect would be virtually impossible to detect.

To provide a rough gauge of the potential importance of spillovers in the current context, I compare the estimated effect of Medicare above - which is calculated based on changes in spending across subregions - to estimates based on changes in spending for the elderly relative to the non-elderly. In a

\footnotetext{
${ }^{23}$ This is an aberration for the AHA data (most technologies first appear with a diffusion rate of about 10 percent), and may in part reflect the fact that for awhile prior to its appearance in the data, the cardiac intensive care unit may not have been distinguished in data collection from the intensive care unit (Russell, 1979).
} 
comparison of spending changes by the elderly relative to the non-elderly, any impact of a change in typical insurance status will impact both age groups and therefore be netted out of the estimate; the differential spending change picks up only the direct impact of one's own age group's insurance, conditional on average insurance coverage.

Consistent with potentially large spillovers, I find that the analysis based on the age-variation in Medicare coverage produces substantially smaller estimates of the impact of Medicare on hospital spending than the analysis based on variation across sub-regions. Table 7 shows mean hospital spending in 1963 and in 1970 for individuals aged 65 to 74 and for individuals aged 55 to 64 . The estimates are based on individual-level data from the 1963 and 1970 Surveys of Health Service Utilization and Expenditures. ${ }^{24}$ The difference-in-differences estimate in Table 7 suggests that the introduction of Medicare is associated with an increase in hospital spending for the elderly relative to the non-elderly of 16 percent (with no covariate adjustment) or 30 percent (covariate adjusted). Even the larger estimate is about one quarter the size of the estimate in Section 3 that, if the effect is limited to the elderly, Medicare is associated with a 115 percent increase in elderly spending. Interestingly, it is quite similar to the 28 percent increase in elderly spending predicted by the Rand estimates (see Appendix B).

Moreover, Table 7 indicates that hospital spending increased substantially for both the non-elderly and the elderly following the introduction of Medicare. Indeed, the simple time series estimate of the change in health spending for the elderly between 1963 and 1970 is over seven times larger than the difference-in-differences estimates. This is further suggestive of a potentially large role for the spillovers hypothesis in reconciling the larger estimates in this paper with the smaller ones implied by the partial equilibrium analysis in the Rand Health Insurance Experiment and in Table 7.

\section{The spread of health insurance and the growth of health spending}

\footnotetext{
${ }^{24}$ See Finkelstein and McKnight (2005) for a detailed description of the data as well as additional estimates. Unfortunately these data do not contain geographic identifiers.
} 
Between 1950 and 1990, real per capita medical spending increased by a factor of five. Over the same period, the average coinsurance rate for the population as a whole fell by about 50 percentage points. ${ }^{25} \mathrm{~A}$ belief that the spread of fee for service health insurance might play an important role in the growth of health spending was one of the factors motivating the subsequent move toward managed care. Based on the results of the Rand experiment, Newhouse (1992) concludes that the spread of health insurance was not quantitatively important in contributing to the increase in spending over this time period.

I implemented the same back of the envelope calculation as in Newhouse (1992), but using the larger spending effects of market-wide changes in health insurance estimated above. The introduction of Medicare decreased the average co-insurance rate in the population by about 7 percentage points. ${ }^{26}$ My smaller estimates suggest that, in its first five years, Medicare was associated with a 23 percent increase in total hospital spending. Extrapolating from these results implies that the 50 percentage point overall decrease in co-insurance rates between 1950 and 1990 could have increased health spending by over 150 percent, and can therefore explain about forty percent of the increase in health spending over this period. ${ }^{27}$

Moreover, I believe these estimates represent a lower bound on the contribution of the spread of health insurance to the rise in health spending. The impact of Medicare on health spending rises over the second five years of its existence, suggesting that the five-year impact does not reflect the full extent of the impact of Medicare on health spending. More importantly, my findings are consistent with Weisbrod's (1991) conjecture that health insurance is likely to have played an important role in the rise in heath care costs by increasing incentives to develop cost-increasing medical technologies. My finding of an impact of Medicare on technology adoption suggests that Medicare increased the expected market size

\footnotetext{
${ }^{25}$ Trends in health spending and average co-insurance rates are from the historical data from the national health accounts (Gibson 1978, Cooper at al., 1976 and CMS 2002). The average co-insurance rate is computed as the ratio of national out of pocket health spending to national total health spending.

${ }^{26}$ The 7 percentage point decrease in co-insurance comes from the fact that Medicare increased the proportion of the elderly with meaningful health insurance by 75 percentage points, the elderly were 10 percent of the population, and Medicare imposed roughly a 5\% co-pay (i.e. a one-day deductible for the first 60 days; average length of stay for the elderly prior to Medicare was 20 days).

${ }^{27}$ Between 1990 and 2000, the average co-insurance rate declined by another 5 percentage points and real per capita spending grew by another 30 percent, suggesting that the spread of insurance may also explain about half of the rise of spending between 1990 and 2000. However, the rise of managed care over this time period makes the application of the estimates of Medicare's spending effect to the impact of health insurance in the 1990s more suspect.
} 
for new cardiac technologies; it may therefore have increased the incentives to develop new medical technologies, and thus the subsequent arrival rate of these new technologies. This dynamic feedback loop could produce long-run effects of Medicare on technological change in medicine and on health spending beyond the ten-year post-Medicare window analyzed here. Although in this paper I can not investigate directly whether Medicare is associated with increased creation of new technologies, empirical evidence of the effect of increased demand on innovation pharmaceutical industry raises the possibility that such a feedback mechanism may be present for hospital technologies as well (Finkelstein 2004, Acemoglu and Linn 2004).

While my findings suggest a potentially much larger role for health insurance in explaining the growth in health spending than previously thought (Newhouse 1992), they are consistent with the consensus among health economists that technological change has been the primary factor behind the rapid increase in health expenditures over the last half century (Newhouse 1992, Fuchs 1996, Cutler 2003). My findings suggest that the impact of market wide changes in health insurance on technology adoption (and perhaps creation) is likely to be an important part of the reason for its disproportionately larger effect of aggregate changes in health insurance than implied by individual-level changes.

\section{Robustness}

I investigated the robustness of the paper's findings to a wide variety of alternative specifications. In this section I discuss three of the major types of robustness analysis performed. I focus on the robustness of the results in Table 3. Sensitivity of the other estimates in the paper was similar (not shown). The results are generally robust to all of these different analyses.

\subsection{Investigating the identifying assumption}

A primary concern is the validity of the identifying assumption that absent the introduction of Medicare in 1966, the different sub-regions of the country would not have exhibited divergent growth from the pre-period patterns. Figure 3 suggests visually that in no year prior to 1965 (or after it for that matter) is there evidence of the dramatic reversal in trend in all outcomes that occurs in 1965. To examine 
this more formally, I limit the data to the years prior to 1966 and re-estimate equation (1); I examine the results of the two-year and five-year tests shown in Table 3 if - counter to fact - I assign some year prior to 1966 as the year in which Medicare was implemented. I do this for all possible years prior to 1966 in which I have enough data to implement each test. The results of this "falsification exercise" are shown in Table 8. They are broadly supportive of the identifying assumption; where the "trust test" yields a statistically significant estimate, all but one of the 69 "false tests" produce smaller (and generally statistically insignificant) estimated effects. ${ }^{28}$

A related concern with the identifying assumption is that different sub-regions of the country might have experienced differential changes in growth in the mid-1960s even absent Medicare. In particular, the poorer South and West might have started to catch up with the richer parts of the country. I therefore verified that the results are robust to including state-specific linear trends in equation (1). This is shown in rows (1) and (2) of Table 9, where, to conserve space, I only report the five-year estimates; other estimates look similar.

It is also possible that the analysis spuriously attributes to Medicare the impact of other Great Society policies implemented in the mid 1960s, or the impact of changing economic conditions around this time more generally. Row 3 shows that the results are robust to adding time-varying covariates for state-levels of socio-economic progress. Specifically, I include real per capita state income, state infant mortality rate, the rate of violent crime (perhaps an indicator of social cohesion), and state population. ${ }^{29}$

I also re-estimated equation (1) using these state-level variables as the dependent variable (and including state instead of county fixed effects). Neither infant mortality nor violent crime shows any evidence of a change after the introduction of Medicare in more affected areas relative to less. However, starting in the early 1970 s real state per capita income starts to rise more quickly than previously in more affected areas relative to less affected areas. This reversal underscores the need for caution in using the empirical approach to estimate the impact of Medicare too far beyond its introduction; however it is

\footnotetext{
${ }^{28}$ Of course the various "false tests" in Table 8 are not independent since they may involve overlapping years.

${ }^{29}$ I am grateful to Larry Katz for providing these data. All variables are measured annually, except state population which is interpolated between censuses. See Katz, Levitt, and Shustorovitch (2003) for more details.
} 
unlikely that the short-term (five-year) estimates of the impact of Medicare are mistakenly picking up the effect of underlying changes in income growth.

Private health insurance coverage for the non-elderly was generally increasing throughout the time period studied. If private health insurance for the non-elderly increases more rapidly after the introduction of Medicare in the areas of the country more affected by Medicare relative to prior trends, part of the estimated impact of Medicare might in fact reflect the impact of increases in health insurance for other age groups. The evidence however helps alleviate this concern. I analyzed private insurance coverage by census region for the non-elderly in the 1959, 1963 and 1970 NHS and found no indication of any systematic increase in private health insurance for the non-elderly in regions more affected by Medicare between 1963 and 1970 relative to the increases across these various regions between 1963 and $1959 .^{30}$

\subsection{Sensitivity to sample definition}

A second set of sensitivity analyses concerns the sample of hospitals included in the analysis. Given the different growth trajectory of the South in the 50s and 60s, as well as the impact of the civil rights movement and the Hill Burton hospital construction program in the South around the time of Medicare's introduction, row 4 of Table 9 reports the results of estimating equation (1) without the four southern subregions in the sample (which constitute about 30 percent of the sample). The estimated impact of Medicare on admissions, employment and total expenditures remains very similar; it is noticeably larger for patient days and beds, and noticeably smaller for payroll expenditures. To look more generally if the results are driven by one particular sub-region of the country, Table 10 reports the results of an informal jackknife-like procedure in which I drop each of the 11 sub-regions in turn from the sample and reestimate equation (1). The point estimates tend to lie in a nice tight pattern around the whole sample, and are almost always statistically significant.

\footnotetext{
${ }^{30}$ Unfortunately neither the 1970 NHS micro data nor the published statistics from the 1959 NHS (available in National Center for Health Statistics, 1960) identify the sub region (of which there are 11), but they do identify the census region (of which there are 4); the main findings of the paper are robust to using this coarser variation. I define the non-elderly as individuals aged 25 to 64 . The findings are similar if I measure private insurance as Blue Cross hospital insurance or any hospital insurance.
} 
All of the results in the paper have been estimated for private hospitals. As discussed above, I suspect that the identification strategy is poorly suited to detecting the impact of Medicare on public hospitals. Nevertheless, if Medicare is associated with a switch in patients from public to private hospitals, looking just at private hospitals could misleadingly imply a larger net impact of Medicare. Row 5 of Table 9 shows that the results are qualitatively robust to including public hospitals in the analysis, suggesting that the estimated impact of Medicare on private hospitals represents a net increase in activity, and not merely a switch of health care provision from public to private hospitals. Consistent with the intuition that the empirical strategy is less likely to detect the impact of Medicare on public hospitals, the estimated impact of Medicare on the sample of all hospitals is lower than that for private hospitals for admissions, employment, payroll and total expenditures (although higher for beds and patient days).

\subsection{Sensitivity to alternative sources of variation}

The final set of sensitivity analyses uses alternative sources of cross-sectional heterogeneity in the impact of Medicare of insurance coverage to identify its effect. In results not reported, I found that the estimates were not sensitive to using variation in insurance coverage at the state or county level instead of the sub-region level. ${ }^{31}$ Row 6 shows that the results are robust to interacting the year fixed effects in equation (1) with an indicator variable for whether the sub-region is one of the eight above the national average in terms of the impact of Medicare on insurance coverage (i.e. 75 percent or more of the elderly without BC hospital insurance in 1963, see Table 1), rather than using the linear measure of percent without insurance to measure Medicare impact as in the baseline specification. Row 7 shows the results are also robust to interacting the year effects with the percent of elderly without any hospital insurance (rather than without Blue Cross hospital insurance).

Since in principle the impact of Medicare depends not only on the proportion of the elderly without insurance but also the proportion of the population that is elderly, Row 8 shows that the results are quite

\footnotetext{
${ }^{31}$ The NHS allows calculation of insurance coverage rates separately within each sub-region by urban and rural areas. Coverage rates are consistently higher in urban areas. I impute state- and county-level insurance estimates based on the sub-region in which the area is located and information from the 1960 census on the percent of the county or state that is urban.
} 
similar if this additional variation is used as well and the year fixed effect in equation (1) are interacted with the share of hospital expenditures in the sub-region covered by elderly insurance. ${ }^{32}$ This is not surprising since in practice there is very little variation in the percent elderly. Across the 11 sub-regions, the percentage of the elderly ranges only from 7.7 to 11.2 (even across counties, the inter-quartile range in percentage elderly is only 8.3 to 12.6 ). To allow for the greater variation in percentage elderly than exists across sub-regions, I also tried re-estimating equation (1) using the variation in the percentage elderly and insurance coverage across counties; the results were very similar (not shown).

\subsection{Implications for magnitude}

The statistical significance of the results in Table 9 is remarkably robust across specifications. The exact magnitudes of course vary somewhat across specifications. However, most lie quite close to the baseline estimates, and all indicate a substantially larger impact of Medicare than what the partial equilibrium estimates of the Rand experiment would have predicted.

Compared to the baseline estimate of an impact of Medicare on admissions of 49 log points (63 percent) and on spending of $40 \log$ points (49 percent), the range of estimates from the alternative specifications in Table 9 suggests that the impact of Medicare on admissions was between 43 and 75 percent, and the impact on spending was between 28 and 60 percent. (By way of comparison, the estimates from the Rand experiment suggest that Medicare would increase total hospital spending by about 5.6 percent).

Sensitivity of the implied magnitude from the weighted analysis was similar (not shown); again, most estimates lay quite close to the baseline findings of a 34 percent increase in admissions and a 23 percent increase in spending. Even the smallest spending estimate from the weighted specifications - which implied a 12 percent increase in spending associated with Medicare - is more than double the Rand estimate.

\footnotetext{
${ }^{32}$ This is calculated as the percent of the elderly without $\mathrm{BC}$ insurance times the proportion of hospital expenses that are elderly. The latter is estimated based on the percent of the population in the sub-region that is elderly, and my estimate from the 1963 Health Care Utilization Survey that hospital spending per individual aged 65 and over was 2.3 times that per individual under age 65 .
} 


\section{Conclusion}

This paper has examined the impact of market-wide changes in health insurance on the health care sector by studying the single largest change in health insurance coverage in U.S. history: the introduction of Medicare in 1965. I find robust evidence that Medicare's introduction is associated with an increase in hospital utilization, measurable hospital inputs (i.e. employment and beds), hospital spending, and hospital technology adoption.

The estimated effects are large. My central estimate is that Medicare is associated with a 23 percent increase in real hospital expenditures (for all ages) between 1965 and 1970, and even larger effects if the analysis is extended through 1975. Even the five-year estimate is four times larger than what evidence from the impact of an individual's health insurance on health spending would suggest. Consistent with a disproportionately larger impact on health spending of market-wide changes in health insurance relative to smaller scale changes, I find evidence that the introduction of Medicare was associated with changes in medical treatment practice. For example, the introduction of Medicare appears to be associated with an increase in treatment intensity, as measured by spending per patient day. Perhaps most importantly, I find that the introduction of Medicare is associated with an increased rate of initial adoption of two then-new cardiac technologies, the open heart surgery facility and the cardiac intensive care unit.

A back of the envelope calculation that extrapolates from the estimated impact of Medicare to the impact of the spread of health insurance more generally suggests that the spread of health insurance between 1950 and 1990 may be able to explain at least 40 percent of the rise in real per capita health spending over this time period. This raises the natural question of whether a similar mechanism can explain why most other OECD countries have also experienced sustained growth in the health care sector over the last half-century (OECD 2004). Interestingly, like the United States, many of these countries also established their national health insurance systems in the 1960s and 1970s (Cutler 2002). Whether other health insurance systems have a similar impact on technological change and health spending as the U.S. Medicare program is an important question for further work. If Medicare's impact on technology use in 
the United States influences the treatment patterns or coverage decisions of other countries' national health care systems, it is also possible that the effect of Medicare on health spending may substantially exceed its direct impact within the United States. This is also an interesting avenue to explore in future research. 


\section{Bibliography}

Acemoglu, Daron and Joshua Linn. 2004. "Market Size in Innovation: Theory and Evidence from the Pharmaceutical Industry." Quarterly Journal of Economics. August.

Anderson, O.W., P. Collette, and J.J. Feldman, 1963. Changes in Family Medical Care Expenditures and Voluntary Health Insurance: A Five-Year Resurvey. Harvard University Press, Cambridge, MA

Andersen, R. and O.W. Anderson, 1967. A Decade of Health Services: Social Survey Trends in Use and Expenditure. University of Chicago Press

Ball, Robert. 1995. "What Medicare’s architects had in mind." Health Affairs. 14(4) Winter.

Baker, Laurence. 1997. "HMOs and Fee for Service Health Care Expenditures: Evidence from Medicare." Journal of Health Economics

Baker, Laurence. 2001. "Managed Care and Technology Adoption in Health Care: Evidence from Magnetic Resonance Imaging." Journal of Health Economics, Vol 20: 395-421.

Baker, Laurence and Ciaran Phibbs. 2002. "Managed care, technology adoption, and health care: the adoption of neonatal intensive care." Rand Journal of Economics, 33(3): 524-548.

Baker, Laurence and S. Shankarkumar. 1998. "Managed Care and Health Care Expenditures: Evidence from Medicare, 1990-1994". Garber ed. Frontiers in Health Policy. Volume 1.

Cooper, Barbara, Nancy Worthington, and Mary McGee. 1976. "Compendium of national health expenditures data." U.S. Department of Health, Education, and Welfare, Social Security Administration, Office of Research and Statistics. DHEW Pub. No. (SSA) 76-11927, Washington, D. C., January.

CMS. 2002. National Health Expenditures. http://cms.hhs.gov/statistics/nhe/default.asp

Cutler, David. 2002. "Equality, Efficiency, and Market Fundamentals: The Dynamics of International Medical Care Reform.” Journal of Economic Literature. September. 881-906.

Cutler, David. 2003. Your Money or Your Life: Strong Medicine for America's Health Care System. Oxford University Press.

Cutler, David and Louise Sheiner. 1998. "Managed Care and the Growth of Medical Expenditures." In Alan Garber (ed). Frontiers in Health Policy Research.

Cutler, David and Richard Zeckhauser. 2000. "The Anatomy of Health Insurance." in Culyer and Newhouse (eds.) Handbook of Health Economics. Elsevier.

Duggan, Mark. 2000. "Hospital Ownership and Public Medical Spending." Quarterly Journal of Economics Nov: 1343-1374.

Eggers, Paul. 2000. "Medicare's End Stage Renal Disease Program." Health Care Financing Review 22(1): $55-60$. 
Epstein, Lenore and Janet Murray. 1967. "The Aged Population of the United States: the 1963 Social Security Survey of the Aged.” US Department of Health, Education and Welfare, Social Security Administration, Office of Research and Statistics. Research Report No. 19.

Feldstein, Martin. 1971. "Hospital Cost Inflation: A Study of Nonprofit Price Dynamics," American Economic Review (61): 853-872.

Feldstein, Martin. 1977. "Quality Change and the Demand for Hospital Care," Econometrica, (45): 16811702.

Feldstein, Martin and Amy Taylor. 1977. "The Rapid Rise of Hospital Costs." Staff Report of the Council of Wage and Price Stability, Executive Office of the President, January 1977.

Finkelstein, Amy. 2004. "Static and Dynamic Effects of Health Policy: Evidence from the Vaccine Industry." Quarterly Journal of Economics, May.

Finkelstein, Amy and Robin McKnight. 2005. "What Did Medicare Do (And Was It Worth It)?” NBER Working Paper 11609.

Fuchs, Victor. 1996. "Economics, Values, and Health Care Reform." Presidential Address of the American Economic Association, American Economic Review, March 1996.

Gibson, Robert. "National Health Expenditures, 1978." Health Care Financing Review Summer 1979.

Glied, Sherry. 2000. "Managed Care”. In Culyer and Newhouse (eds). Handbook of Health Economics.

Glied, Sherry and Joshua Graff Zivin, "How Do Doctors Behave When Some (But Not All) of Their Patients are in Managed Care?" Journal of Health Economics, 21(2002): 337-353.

Gruber, Jonathan. Forthcoming. "Medicaid" in Moffit, Robert (ed.) Means Tested Transfer Programs in the United States.

Katz, Lawrence, Steven Levitt, and Ellen Shustorovich. 2003. "Prison Conditions, Capital Punishment, and Deterrence." American Law and Economics Review 5: 318-43.

Keeler, Emmett, Joan Buchanan, John Rolph, Janet Hanley and David Reboussin. 1988. "The demand for episodes of metical treatment in the health insurance experiment." Rand Working Paper R-3455-HHS.

Manning, Willard, Joseph Newhouse, Naihua Duan, Emmett Keeler, Arleen Leibowitz, and Susan Marquis. 1987. "Health Insurance and the Demand for Medical Care: Evidence from a Randomized Experiment." American Economic Review Vol 77, No 3, pp. 251-277.

McGuire, Thomas and Pauly, Mark. 1991. "Physician Response to Fee Changes with Multiple Payers." Journal of Health Economics 10: 385-410.

National Center for Health Statistics, 1960. "Health Statistics for the U.S. National Health Survey; Interim Report on Health Insurance. United States July - December 1959”. Washington, DC.

National Center for Health Statistics. 1964. "Health Insurance Coverage: United States, July 1962-June 1963." August, Number 11. Washington DC: US Department of Health, Education and Welfare. http://www.cdc.gov/nchs/data/series/sr_10/sr10_011acc.pdf 
National Center for Health Statistics, 2002. Health, United States, 2002 With Chartbook on Trends in the Health of Americans. Hyattsville, Maryland: 2002.

Newhouse, Joseph. 1992. "Medicare Care Costs: How Much Welfare Loss?” Journal of Economic Perspectives, 6(3): 3-21.

Newhouse, Joseph and the Insurance Experiment Group. 1993. Free for All? Lessons from the RAND Health Insurance Experiment. Harvard University Press: Cambridge MA.

Newhouse, Joseph. 2002. Pricing the Priceless: A Health Care Conundrum. MIT Press, Cambridge MA.

Newhouse, Joseph and M. Susan Marquis. 1978. "The Norms Hypothesis and the Demand for Medical Care.” Journal of Human Resources 13:159-1982.

OECD 2004. OECD Health Data 2000 - A Comparative Analysis of 30 OECD Countries. http://www.oecd.org/document/16/0,2340,en_2649 34631_2085200_1_1_1_1,00.html

Russell, Louise B. 1977. "The Diffusion of Hospital Technologies: Some Econometric Evidence." Journal of Human Resources 12(4): 482-502.

Russell, Louise B. 1979. "Technology in Hospitals: Medical Advances and Their Diffusion.” The Brookings Institution: Washington D.C.

Russell, Louise B and Carol S. Burke. 1975. “Technological Diffusion in the Hospital Sector.” Prepared for the National Science Foundation, Office of National R\&D Assessment. October.

Skinner, Jonathan and Douglas Staiger. 2005. "Technology adoption from hybrid corn to beta blockers." NBER Working Paper 11251.

Somers, Herman and Anne Somers 1967. Medicare and the Hospitals: Issues and Prospects. The Brookings Institution: Washington DC.

Stevens, Rosemary. 1999. In Sickness and In Wealth: American Hospitals in the $20^{\text {th }}$ Century. Johns Hopkins University Press.

Stevens, Robert and Rosemary Stevens. 1974. Welfare Medicine in America: A Case Study of Medicaid. The Free Press: New York.

US Department of Health Education and Welfare. 1969. "Hospital and Surgical Insurance Coverage in the United States, July - December 1967.” Monthly Vital Statistics Report 18(3): Supplement June 23.

United States Senate Special Committee on Aging. 1963. "Medical Assistance for the Aged: The KerrMills Program 1960-1963," U.S. Government Printing Office, Washington, D.C., October 1963.

United States Senate. 1970. "Medicare and Medicaid: Problems, Issues and Alternatives." Report of the Staff to the Committee on Finance. Government Printing Office: Washington.

Weisbrod, Burton. 1991. "The Health Care Quadrilemma: An Essay on Technological Change, Insurance, Quality of Care, and Cost Containment.” Journal of Economic Literature 29(2): 523-552. 
Zweifel, Peter and Willard Manning. 2000. "Moral hazard and consumer incentives in health care" in Anthony Culyer and Joseph Newhouse (eds.) Handbook of Health Economics 
Table 1: Percent of Elderly Without Hospital Insurance, 1963

Any Insurance Blue Cross

\begin{tabular}{lll} 
New England (CT, ME, MA, NH, RI, VT) & 0.37 & 0.49 \\
Middle Atlantic (NJ, NY, PA) & 0.41 & 0.60 \\
East North Central, Eastern Part (MI, OH) & 0.32 & 0.55 \\
East North Central, Western Part (IL, IN, WI) & 0.42 & 0.75 \\
West North Central (IA, KS, MN, MO, NE, ND, SD) & 0.47 & 0.81 \\
South Atlantic, Upper Part (DE, DC, MD, VA, WV) & 0.45 & 0.75 \\
South Atlantic, Lower Part (FL, GA, NC, SC) & 0.50 & 0.81 \\
East South Central (AL, KY, MS, TN) & 0.57 & 0.88 \\
West South Central (AR, LA, OK, TX) & 0.55 & 0.85 \\
Mountain (AZ, CO, ID, MT, NV, NM, UT, WY) & 0.50 & 0.78 \\
Pacific (OR, WA, CA, AK, HI) & 0.52 & 0.87 \\
\hline \hline
\end{tabular}

Note: Data are from individuals aged 65 and over in the 1963 National Health Survey. Sample size is 12,757. Minimum sample size for a sub-region is 377 .

Table 2: Description of Dependent Variables from the AHA data

\begin{tabular}{|c|c|c|c|c|c|}
\hline \multirow{2}{*}{$\begin{array}{l}\text { Outcome } \\
\text { Category }\end{array}$} & \multirow[t]{2}{*}{ Dependent Variable } & \multirow{2}{*}{$\begin{array}{l}\text { First year } \\
\text { data } \\
\text { present }\end{array}$} & \multicolumn{3}{|c|}{ Sample Mean $(1962-1964)$} \\
\hline & & & $\begin{array}{c}\text { Full } \\
\text { Sample }\end{array}$ & $\begin{array}{c}\text { North \& } \\
\text { Northeast }\end{array}$ & $\begin{array}{c}\text { South \& } \\
\text { West }\end{array}$ \\
\hline \multirow{2}{*}{$\begin{array}{l}\text { Expenditures } \\
(\$ 1960, ’ 000)\end{array}$} & Total & 1955 & 1,410 & 1,679 & 1,098 \\
\hline & Payroll & 1948 & 870 & 1,054 & 658 \\
\hline \multirow[t]{2}{*}{ Major Inputs } & Beds & 1948 & 125 & 152 & 96 \\
\hline & Employment & 1951 & 229 & 278 & 175 \\
\hline \multirow[t]{2}{*}{ Utilization } & Inpatient Admissions & 1948 & 4,448 & 4,958 & 3,895 \\
\hline & Inpatient Days & 1955 & 36,410 & 45,254 & 26,809 \\
\hline
\end{tabular}

Note: All variables are measured annually at the hospital level for private hospitals. Employment and payroll expenditures exclude residents and interns. 
Table 3: Impact of Medicare on Hospital Behavior

\begin{tabular}{|c|c|c|c|c|c|c|}
\hline & \multicolumn{2}{|c|}{ Utilization } & \multicolumn{2}{|c|}{ Inputs } & \multicolumn{2}{|c|}{ Expenditures } \\
\hline & $\begin{array}{l}\text { Log } \\
\text { Admissions }\end{array}$ & $\begin{array}{l}\text { Log Patient } \\
\text { Days }\end{array}$ & $\begin{array}{l}\text { Log } \\
\text { Employment }\end{array}$ & Log Beds & $\begin{array}{l}\text { Log Payroll } \\
\text { Expenditures }\end{array}$ & $\begin{array}{l}\text { Log Total } \\
\text { Expenditures }\end{array}$ \\
\hline $\begin{array}{l}\text { 1. First Two Years: } \\
(1967-1965 \text { vs. } \\
1965-1963)\end{array}$ & $\begin{array}{l}0.302 * * \\
(0.040)\end{array}$ & $\begin{array}{l}0.298 * * * \\
(0.009)\end{array}$ & $\begin{array}{l}0.268 * * * \\
(0.006)\end{array}$ & $\begin{array}{l}0.074 \\
(0.518)\end{array}$ & $\begin{array}{l}0.421 * * * \\
(0.0001)\end{array}$ & $\begin{array}{l}0.330 * * * \\
(0.0002)\end{array}$ \\
\hline $\begin{array}{l}\text { 2. First Five Years: } \\
(1970-1965 \text { vs. } \\
1965-1960)\end{array}$ & $\begin{array}{l}0.646^{* * *} \\
(0.004)\end{array}$ & $\begin{array}{l}0.435 * * \\
(0.014)\end{array}$ & $\begin{array}{l}0.386 * * \\
(0.012)\end{array}$ & $\begin{array}{l}0.279 * \\
(0.093)\end{array}$ & $\begin{array}{l}0.715^{* * *} \\
(0.0000)\end{array}$ & $\begin{array}{l}0.532 * * * \\
(0.0009)\end{array}$ \\
\hline $\begin{array}{l}\text { 3. First } 10 \text { Years } \\
(1975-1965 \text { vs. } \\
1965-1955)\end{array}$ & $\begin{array}{l}0.673 * * \\
(0.014)\end{array}$ & $\begin{array}{l}0.479 * * \\
(0.036)\end{array}$ & $\begin{array}{l}0.457 * * * \\
(0.010)\end{array}$ & $\begin{array}{l}0.644 * * * \\
(0.0001)\end{array}$ & $\begin{array}{l}0.572 * * * \\
(0.009)\end{array}$ & $\begin{array}{l}0.492 * * * \\
(0.009)\end{array}$ \\
\hline $\begin{array}{l}\text { 4. Second Five Yrs: } \\
(1975-1970 \text { vs. } \\
1965-1960)\end{array}$ & $\begin{array}{l}0.361 * * \\
(0.028)\end{array}$ & $\begin{array}{l}0.198 \\
(0.206)\end{array}$ & $\begin{array}{l}0.287 * * \\
(0.018)\end{array}$ & $\begin{array}{l}0.323 * * * \\
(0.006)\end{array}$ & $\begin{array}{l}0.554 * * * \\
(0.0005)\end{array}$ & $\begin{array}{l}0.414 * * * \\
(0.0014)\end{array}$ \\
\hline $\mathrm{N}$ & 112,323 & 86,401 & 99,523 & 119,402 & 94,789 & 77,598 \\
\hline \multicolumn{7}{|c|}{ Separate regression: Weighted by hospital size in pre-period } \\
\hline $\begin{array}{l}\text { 5. First Five Years: } \\
\text { (1970-1965 vs. } \\
1965-1960)\end{array}$ & $\begin{array}{l}0.386^{* * *} \\
(0.004)\end{array}$ & $\begin{array}{l}0.407 * * * \\
(0.0004)\end{array}$ & $\begin{array}{l}0.505^{* * *} \\
(0.0001)\end{array}$ & $\begin{array}{l}0.353 * * * \\
(0.001)\end{array}$ & $\begin{array}{l}0.519 * * * \\
(0.0006)\end{array}$ & $\begin{array}{l}0.277^{* *} \\
(0.05)\end{array}$ \\
\hline $\mathrm{N}$ & 89,249 & 72,129 & 80,922 & 93,282 & 77,041 & 65,373 \\
\hline
\end{tabular}

Notes: Table reports results from estimating equation (1) and calculating test statistics as shown in equation (2). Column heading shows dependent variable. P-values are in parentheses and are calculated allowing for an arbitrary variance-covariance matrix within each state. ${ }^{* *},{ }^{* *}, *$ denotes significance at the 1 percent, 5 percent, and 10 percent level respectively. Differences in sample size across the columns primarily reflect different starting years for the various variables (see Table 2); however, to some extent they also reflect different proportions of missing data (see Appendix A). Results are not sensitive to limiting all variables to a common sample. Sample size for the weighted regression is 10 to 20 percent lower due to difficulties in linking hospitals across years (see text); unweighted analysis on this smaller sample yields very similar results to the unweighted analysis on the full sample. 
Table 4: Impact of Medicare on Treatment Intensity

\begin{tabular}{|c|c|c|c|c|}
\hline & $\begin{array}{l}\text { Log Total } \\
\text { Expenditures } \\
\text { Per Patient Day }\end{array}$ & $\begin{array}{l}\text { Log Payroll } \\
\text { Expenditures } \\
\text { Per Patient Day }\end{array}$ & $\begin{array}{l}\text { Log } \\
\text { Employment Per } \\
\text { Patient Day }\end{array}$ & $\begin{array}{l}\text { Log Beds Per } \\
\text { Patient Day }\end{array}$ \\
\hline $\begin{array}{l}\text { 1. First Two Years: } \\
\text { (1967-1965 vs. } \\
1965-1963)\end{array}$ & $\begin{array}{l}-0.050 \\
(0.47)\end{array}$ & $\begin{array}{l}0.077 \\
(0.25)\end{array}$ & $\begin{array}{l}-0.050 \\
(0.63)\end{array}$ & $\begin{array}{l}-0.183 * * \\
(0.03)\end{array}$ \\
\hline $\begin{array}{l}\text { 2. First Five Years: } \\
(1970-1965 \text { vs. } \\
1965-1960)\end{array}$ & $\begin{array}{l}-0.025 \\
(0.77)\end{array}$ & $\begin{array}{l}0.148 \\
(0.18)\end{array}$ & $\begin{array}{l}-0.055 \\
(0.59)\end{array}$ & $\begin{array}{l}-0.088 \\
(0.30)\end{array}$ \\
\hline $\begin{array}{l}\text { 3. First } 10 \text { Years } \\
(1975-1965 \text { vs. } \\
1965-1955)\end{array}$ & $\begin{array}{l}0.068 \\
(0.60)\end{array}$ & $\begin{array}{l}0.141 \\
(0.33)\end{array}$ & $\begin{array}{l}0.005 \\
(0.96)\end{array}$ & $\begin{array}{l}0.194 * * \\
(0.03)\end{array}$ \\
\hline $\begin{array}{l}\text { 4. Second Five Yrs: } \\
(1975-1970 \text { vs. } \\
1965-1960)\end{array}$ & $\begin{array}{l}0.189 * * \\
(0.017)\end{array}$ & $\begin{array}{l}0.255^{* * *} \\
(0.010)\end{array}$ & $\begin{array}{l}0.154 \\
(0.13)\end{array}$ & $\begin{array}{l}0.225 * * * \\
(0.007)\end{array}$ \\
\hline $\mathrm{N}$ & 77,369 & 75,999 & 85,782 & 86,400 \\
\hline
\end{tabular}

Notes: Table reports results from estimating equation (1) and calculating test statistics as shown in equation (2). Column heading shows dependent variable. P-values are in parentheses and are calculated allowing for an arbitrary variance-covariance matrix within each state. ${ }^{* * *},{ }^{* *},{ }^{*}$ denotes significance at the 1 percent, 5 percent, and 10 percent level respectively. 
Table 5: Medicare and the adoption of the Open Heart Surgery Facility

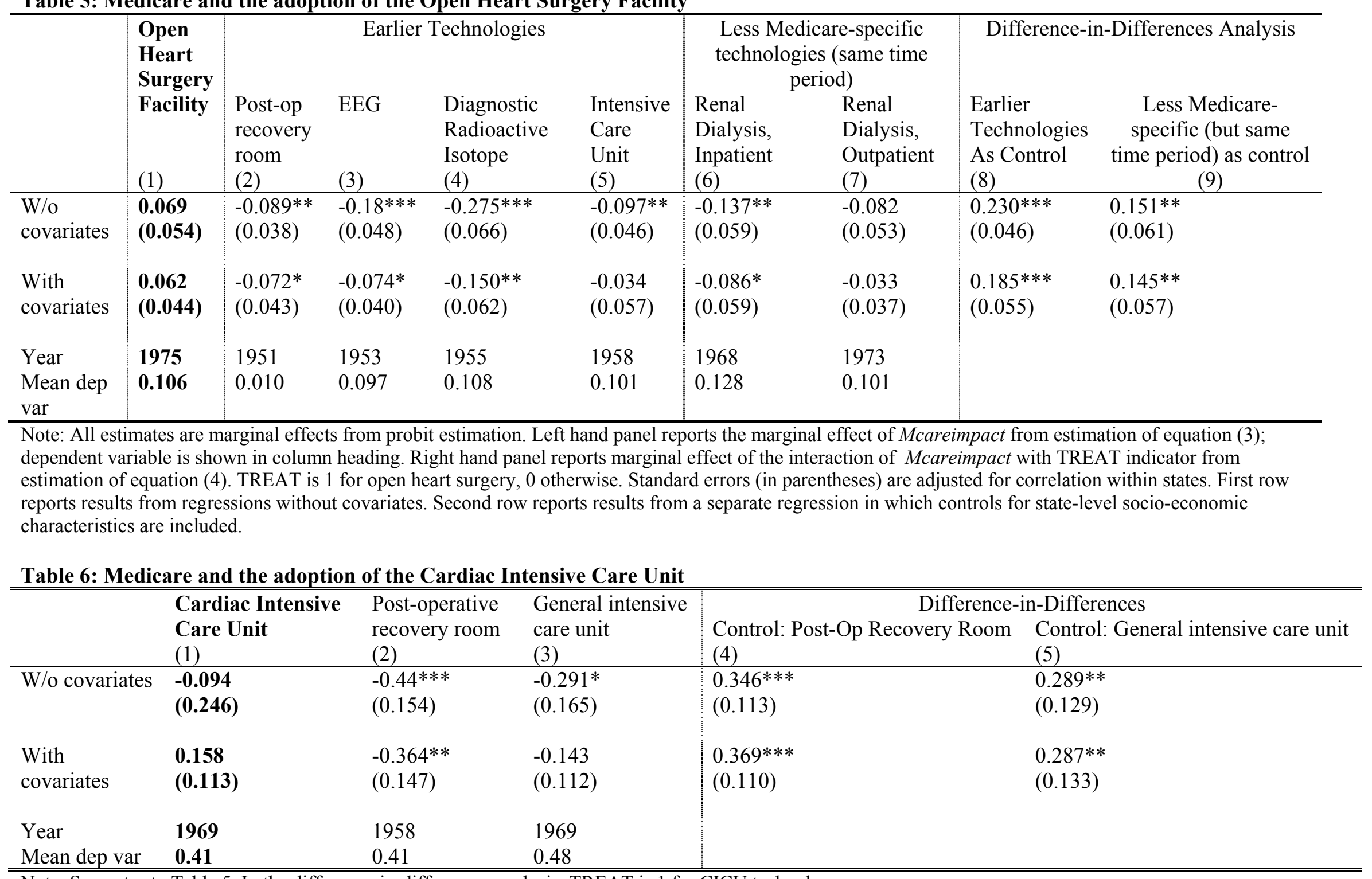

Note: See notes to Table 5. In the difference-in-differences analysis, TREAT is 1 for CICU technology. 
Table 7: Changes in hospital spending for individuals aged 65-74 and individuals aged 55-64

\begin{tabular}{|c|c|c|c|c|c|c|}
\hline & 1963 & 1970 & Difference & $\begin{array}{c}\text { Difference } \\
\text { (Covariate- } \\
\text { Adjusted) }\end{array}$ & $\begin{array}{l}\text { Difference- } \\
\text { in- } \\
\text { Difference }\end{array}$ & $\begin{array}{c}\text { Difference-in- } \\
\text { Difference } \\
\text { (Covariate } \\
\text { Adjusted) }\end{array}$ \\
\hline Ages $65-74$ & 281 & 919 & $\begin{array}{l}639 * * * \\
(125)\end{array}$ & $\begin{array}{l}651^{* * * *} \\
(133)\end{array}$ & & \\
\hline Ages 55-64 & 245 & 840 & $\begin{array}{l}595 * * * \\
(127)\end{array}$ & $\begin{array}{l}570 * * * \\
(116)\end{array}$ & & \\
\hline Difference & $\begin{array}{l}35 \\
(63)\end{array}$ & $\begin{array}{l}80 \\
(167)\end{array}$ & & & $\begin{array}{l}44 \\
(178)\end{array}$ & $\begin{array}{l}86 \\
(171)\end{array}$ \\
\hline
\end{tabular}

Note: All dollars are in year 2000 dollars. Data are from the 1963 and 1970 Surveys of Health Service Utilization and Expenditures. $\mathrm{N}=3,030$ (pooled sample). Robust standard errors are in parentheses. ${ }^{* * *}, * *, *$ indicates statistical significance at the 1 percent, 5 percent and 10 percent level respectively. Covariate-adjusted estimates control for gender, marital status, age, age-squared, and indicators for education group (6 or fewer years of school, between 6 and 12 years of school, and 12 or more years of school).

Table 8: Falsification exercise on pre-period (actual estimates from Table 3 are given in bold).

\begin{tabular}{|c|c|c|c|c|c|}
\hline \multicolumn{2}{|c|}{ Utilization } & \multicolumn{2}{|c|}{ Inputs } & \multicolumn{2}{|c|}{ Expenditures } \\
\hline $\log$ & Log Patient & $\log$ & Log Beds & Log Payroll & Log Total \\
\hline Admissions & Days & Employment & & Expenditures & Expenditures \\
\hline \multicolumn{6}{|c|}{ Distribution of estimates from two-year test } \\
\hline$-0.208^{*}$ & & & -0.106 & $-0.438 * * *$ & \\
\hline-0.154 & & & -0.056 & -0.240 & \\
\hline-0.111 & & -0.154 & -0.054 & -0.077 & \\
\hline-0.078 & & -0.128 & -0.053 & -0.033 & \\
\hline-0.073 & -0.150 & -0.121 & -0.046 & -0.016 & -0.155 \\
\hline-0.050 & -0.043 & -0.104 & -0.028 & -0.001 & -0.140 \\
\hline-0.054 & -0.026 & -0.032 & 0.015 & 0.091 & -0.120 \\
\hline-0.044 & -0.025 & 0.003 & 0.042 & 0.107 & -0.081 \\
\hline-0.013 & -0.020 & 0.009 & 0.050 & 0.137 & 0.005 \\
\hline 0.032 & -0.012 & 0.101 & 0.074 & 0.145 & 0.019 \\
\hline 0.290 & 0.019 & $0.268 * * *$ & 0.078 & 0.145 & 0.167 \\
\hline $0.302 * *$ & $0.298 * * *$ & $0.269 * *$ & 0.160 & $0.421 * * *$ & $0.330 * * *$ \\
\hline \multicolumn{6}{|c|}{ Distribution of estimates from five-year test } \\
\hline-0.283 & & & -0.129 & $-0.648 * * *$ & \\
\hline 0.061 & & & 0.028 & -0.057 & \\
\hline 0.098 & & -0.225 & 0.032 & 0.055 & \\
\hline 0.243 & & 0.035 & 0.081 & 0.138 & \\
\hline $0.398 *$ & & 0.213 & 0.097 & 0.246 & \\
\hline $0.483 * *$ & -0.196 & $0.306^{*}$ & 0.109 & 0.319 & $-0.396^{*}$ \\
\hline $0.646 * * *$ & $0.435 * * *$ & $0.386 * *$ & $0.279 *$ & $0.715 * * *$ & $0.532 * * *$ \\
\hline
\end{tabular}

Note: Table reports the results from estimating the first two years test and the first five years test (see Table 3 and equation 2 for details) when equation (1) is estimated on a sample restricted to years 1965 and earlier, and a randomly assigned year prior to 1965 is selected for the test. Bold estimates are the actual estimate from Table 3 . $* * *, * *, *$ denotes significance at the 1 percent, 5 percent, and 10 percent level respectively. 
Table 9: Estimated Impact of Medicare in First Five Years; Alternative Specifications

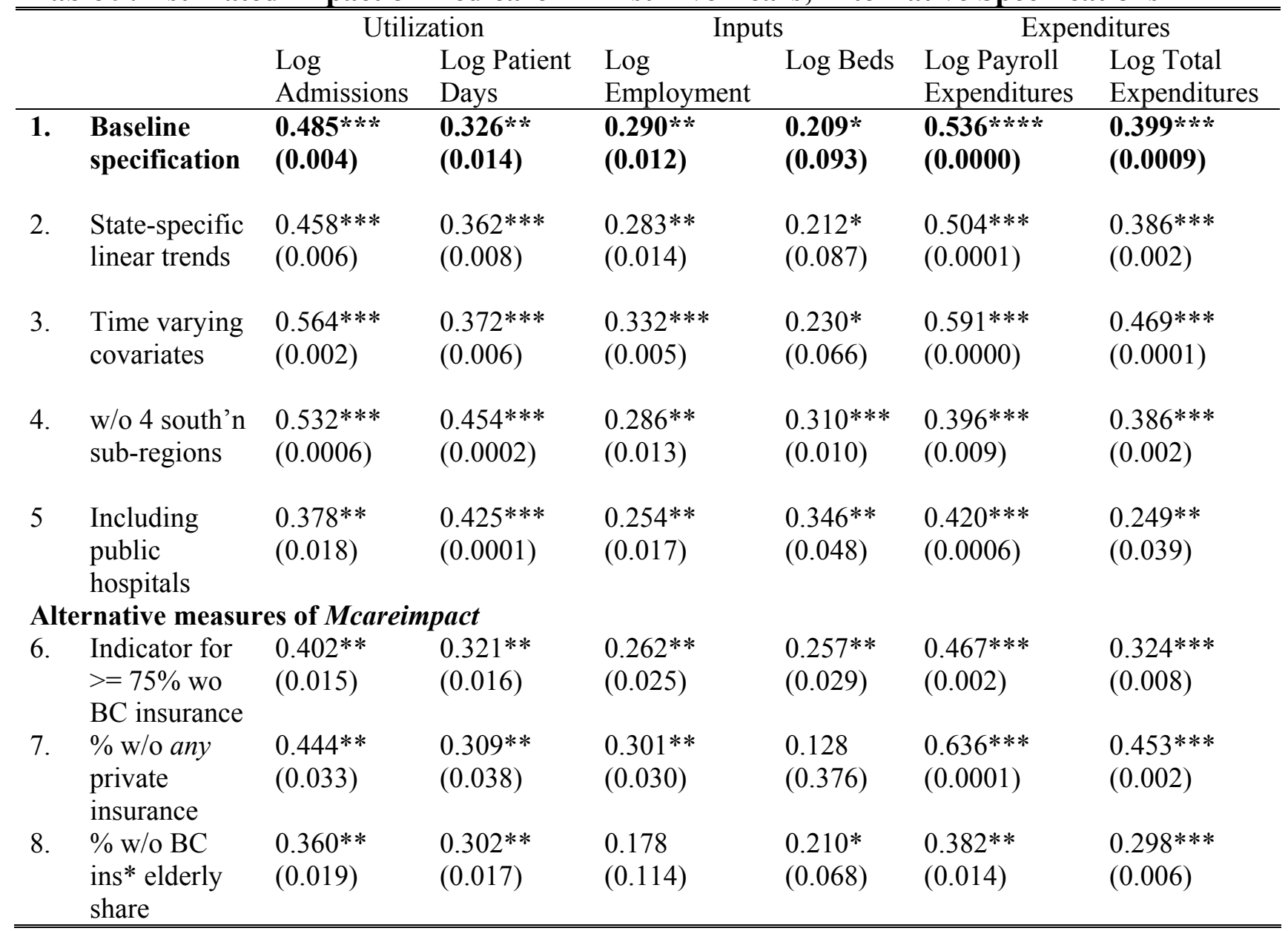

Notes: Table reports implied impact of Medicare from estimating a variant of the baseline specification of equation (1), performing the "First Five Years" test in equation (2), and the translating the test statistic into the implied impact of Medicare. This last step is done so that the estimates are directly comparable across specifications. Pvalues are in parentheses and are calculated allowing for an arbitrary variance-covariance matrix within each state. $* * *, * *, *$ denotes significance at the 1 pct, 5 pct, and 10 pct level respectively.

- Row 1: Baseline specification: Estimates are as shown in Table 3, then multiplied by 0.75 (the nationwide impact of Medicare on insurance coverage as measured by percent of elderly without BC insurance in 1963).

- Row 2: Row 1 with state-specific linear trends included in the regression.

- Row 3: Row 1 with time-varying state covariates (real per capita income, infant mortality rate, violent crime, and population) added to the regression.

- Row 4: Row 1 without 4 Southern sub-regions (and therefore multiplying by 0.7 , the average $\%$ of the elderly without BC insurance in the non-Southern United States).

- Row 5: Row 1 with public hospitals added in

- Row 6: Mcareimpact in equation (1) is measured with an indicator variable for sub-region has $>=75 \%$ of elderly w/o BC insurance rather than a linear measure of $\%$ of the elderly w/o BC insurance as in the baseline specification. Estimates are multiplied by 2.7 since on average areas $>=75 \%$ or more of elderly w/o BC insurance have 28 percentage points less insurance than areas where $<75 \%$ of the elderly are w/o BC insurance.

- Row 7: Mcareimpat is measured as the percent of the elderly without any private hospital insurance. Estimates are therefore multiplied by 0.45 (the percent of the elderly without any hospital insurance).

- Row 8: Mcareimpact is measured using variation in \% of population that is elderly as well as \% of elderly w/o $\mathrm{BC}$ insurance (see text for more details). Estimates are therefore multiplied by 0.15 (i.e. $0.75 * 0.20$ where 0.75 is the average percentage point increase in elderly insurance due to Medicare and 0.20 is the average share of the elderly in hospital expenditures. 
Table 10: Robustness of estimates to omitting each sub-region (First Five Years)

\begin{tabular}{lllllll}
\hline \hline Omitted sub-region & $\begin{array}{l}\text { Log } \\
\text { Admissions }\end{array}$ & $\begin{array}{l}\text { Log } \\
\text { Patient } \\
\text { Days }\end{array}$ & $\begin{array}{l}\text { Log } \\
\text { Employ- } \\
\text { ment }\end{array}$ & Log Beds & $\begin{array}{l}\text { Log Payroll } \\
\text { Expenditures }\end{array}$ & $\begin{array}{l}\text { Log Total } \\
\text { Expenditures }\end{array}$ \\
\hline None (base case) & $\mathbf{0 . 6 4 6 * * *}$ & $\mathbf{0 . 4 3 5 * *}$ & $\mathbf{0 . 3 8 6 * *}$ & $\mathbf{0 . 2 7 9 *}$ & $\mathbf{0 . 7 1 5 * * *}$ & $\mathbf{0 . 5 3 2 * * *}$ \\
New England & $0.531^{* *}$ & $0.482^{* *}$ & $0.404^{* *}$ & 0.291 & $0.923^{* * *}$ & $0.609^{* * *}$ \\
Middle Atlantic & $0.637^{* *}$ & $0.395^{* *}$ & $0.338^{*}$ & 0.140 & $0.607 * * *$ & $0.519^{* * *}$ \\
East No. Cent'l, Eastn & $0.792^{* * *}$ & $0.432^{* *}$ & $0.442^{* * *}$ & $0.353^{* *}$ & $0.745^{* * *}$ & $0.549^{* * *}$ \\
East No. Cent'l, Westn & $0.675^{* * *}$ & $0.433^{* *}$ & $0.393^{* *}$ & $0.282^{*}$ & $0.749^{* * *}$ & $0.561^{* * *}$ \\
West North Central & $0.652^{* * *}$ & $0.420^{* *}$ & $0.419^{* * *}$ & 0.250 & $0.747^{* * *}$ & $0.550^{* * *}$ \\
South Atlantic, Upper & $0.648^{* * *}$ & $0.442^{* *}$ & $0.389^{* *}$ & $0.280^{*}$ & $0.723^{* * *}$ & $0.541^{* * *}$ \\
South Atlantic, Lower & $0.663^{* * *}$ & $0.469^{* * *}$ & $0.408^{* * *}$ & $0.292^{*}$ & $0.721^{* * *}$ & $0.566^{* * *}$ \\
East South Central & $0.634^{* * *}$ & $0.436^{* *}$ & $0.329^{* *}$ & $0.287^{*}$ & $0.604^{* * *}$ & $0.429^{* *}$ \\
West South Central & $0.698^{* * *}$ & $0.526^{* * *}$ & $0.426^{* * *}$ & $0.358^{* *}$ & $0.707^{* * *}$ & $0.611^{* * *}$ \\
Mountain & $0.625^{* * *}$ & $0.424^{* *}$ & $0.367^{* *}$ & $0.278^{*}$ & $0.684^{* * *}$ & $0.492^{* * *}$ \\
Pacific & $0.539^{* *}$ & $0.330^{*}$ & $0.337^{* *}$ & 0.252 & $0.680^{* * *}$ & $0.432^{* *}$ \\
\hline \hline
\end{tabular}

Note: Table shows "First Five Years test" (see equation 2) performed after estimating equation (1) omitting the subregion indicated in the left-hand column. Column heading indicate dependent variable. Base case results are from Table $3 . * * *, * *, *$ denotes significance at the 1 percent, 5 percent, and 10 percent level respectively. 


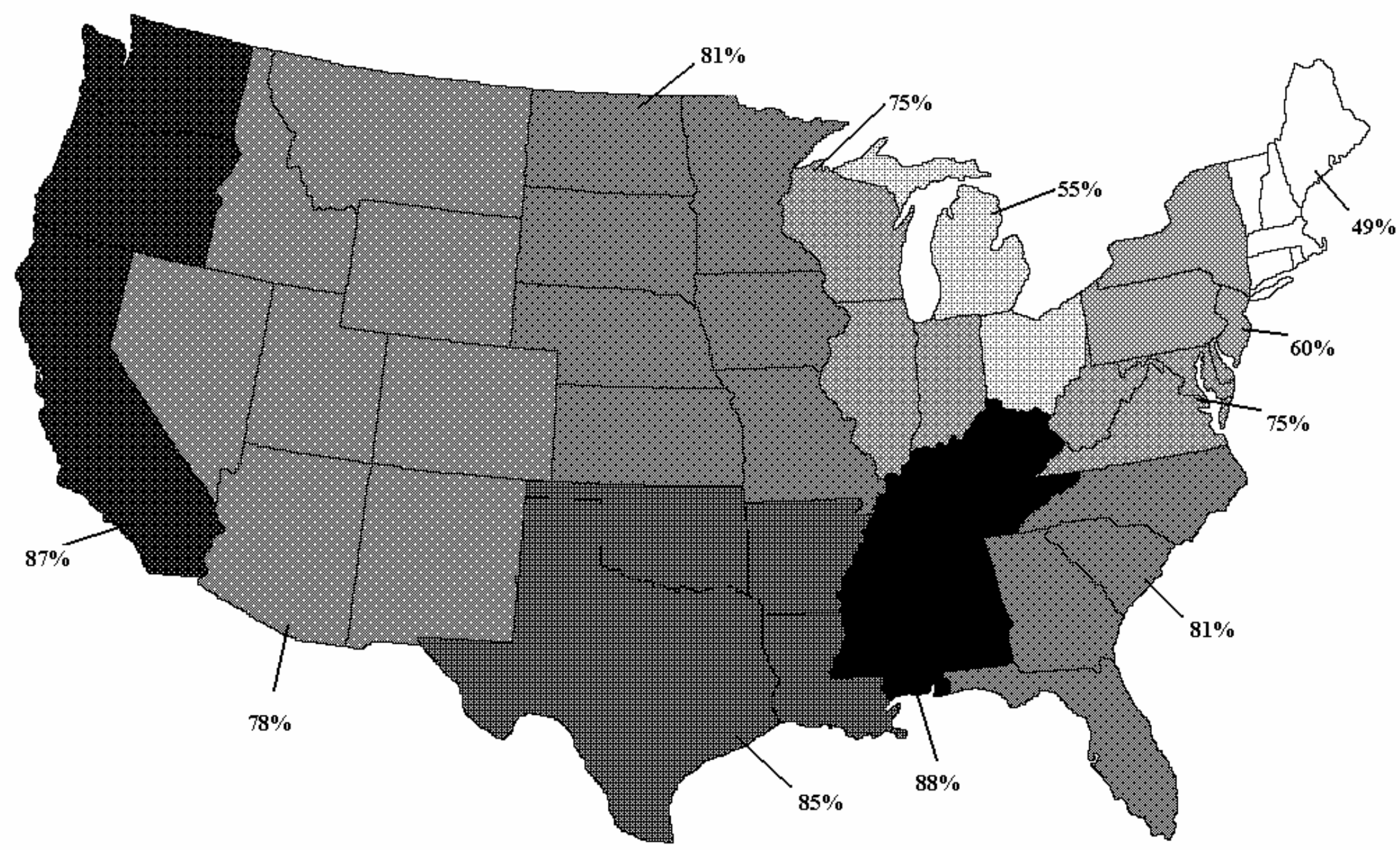

Figure 1: Percent of Elderly Without Blue Cross Hospital Insurance by Sub-region. Data are from 1963 National Health Interview Survey. Darker areas denote a higher percent without Blue Cross Health Insurance; Lighter areas denote a lower percent without Blue Cross health insurance. 


\section{Figure 2: National Time Series Patterns}
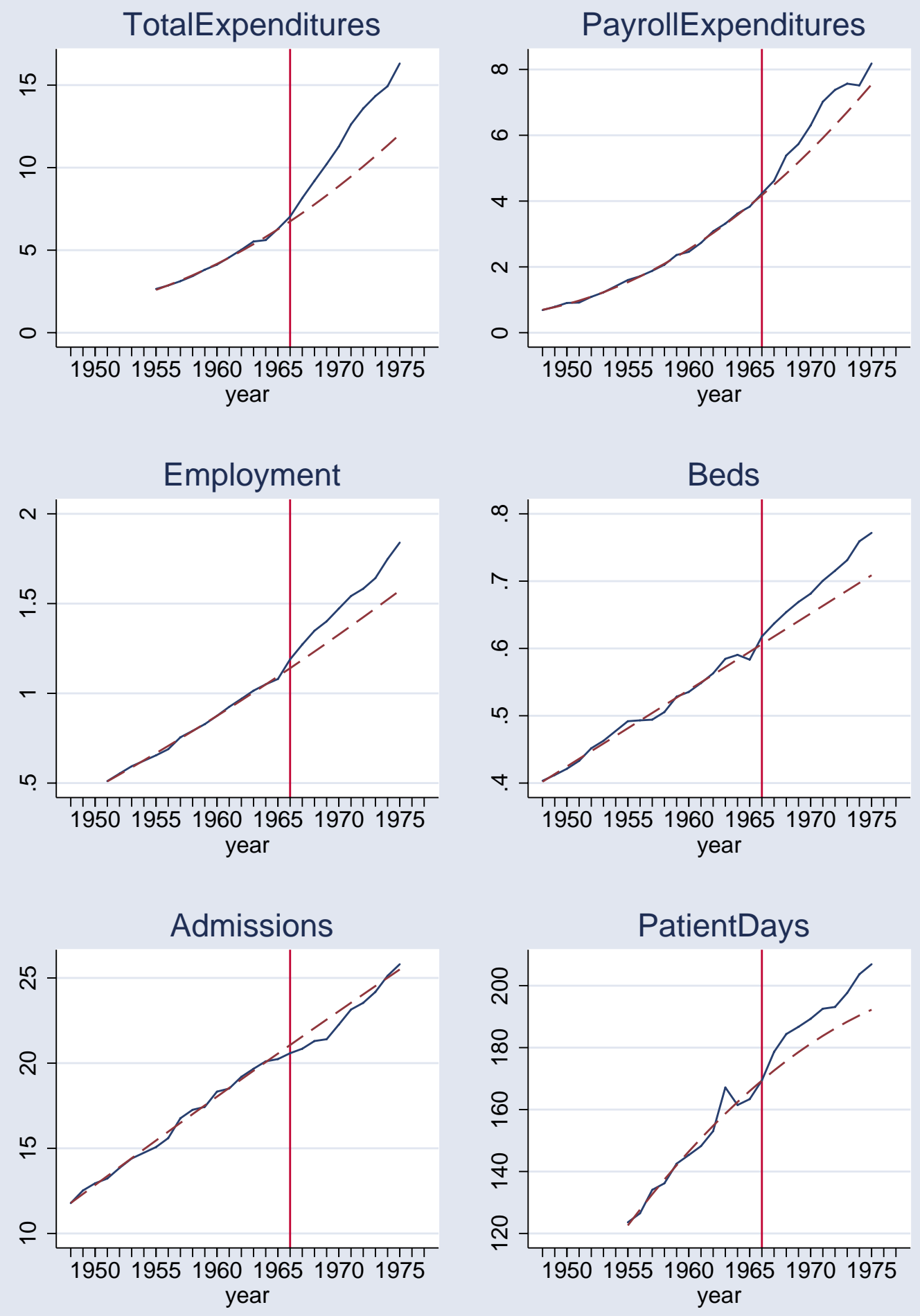

Note: Y-axis scale is in millions. Expenditure variables are in constant (1960) dollars. Dashed line shows quadratic time series trend predicted off of the pre-1965 data. 


\section{Figure 3: Baseline Specification}
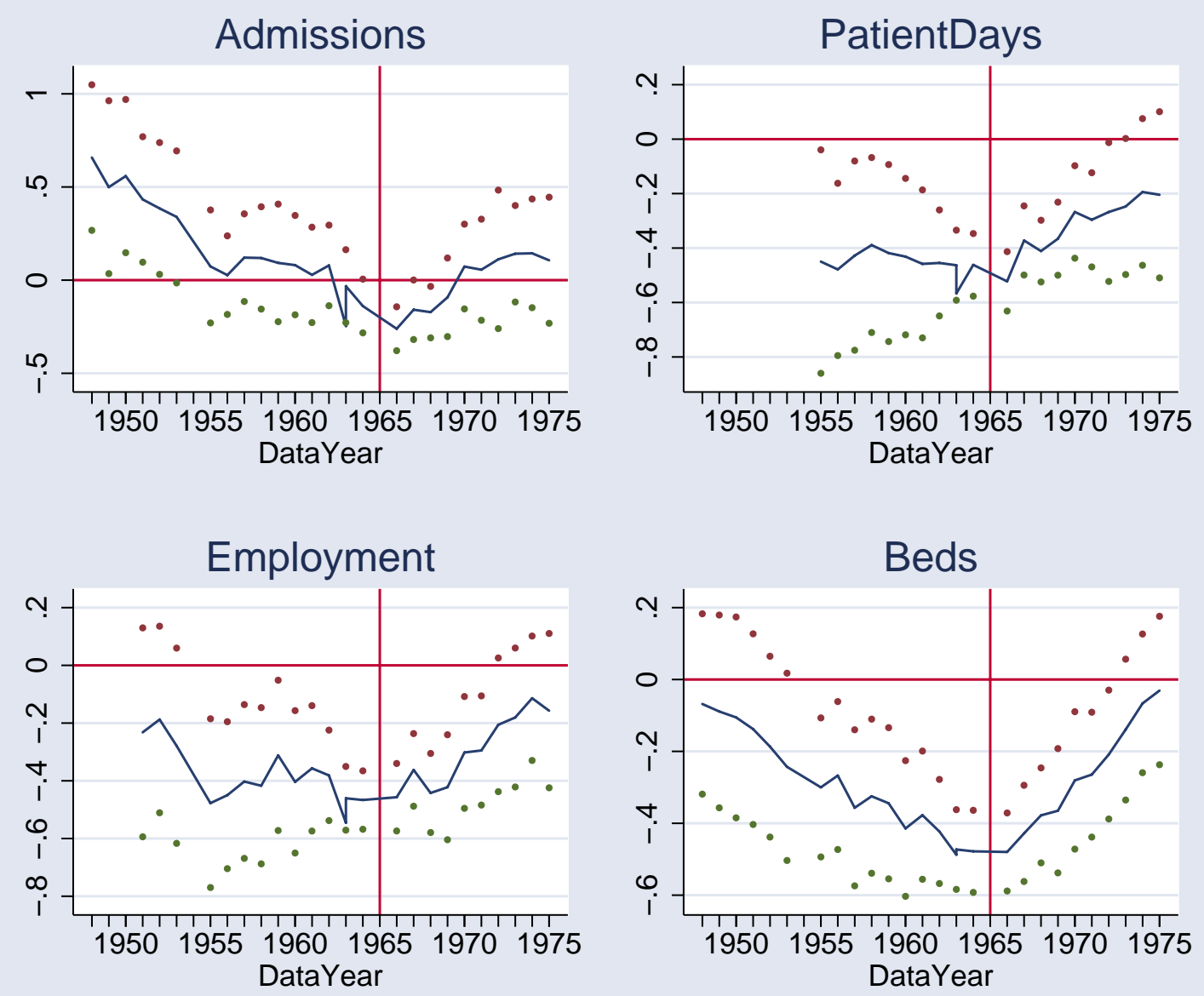

PayrollExpenses

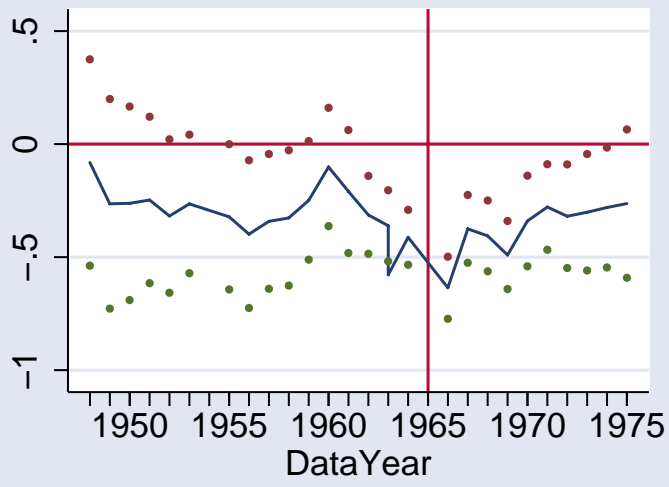

\section{TotalExpenses}

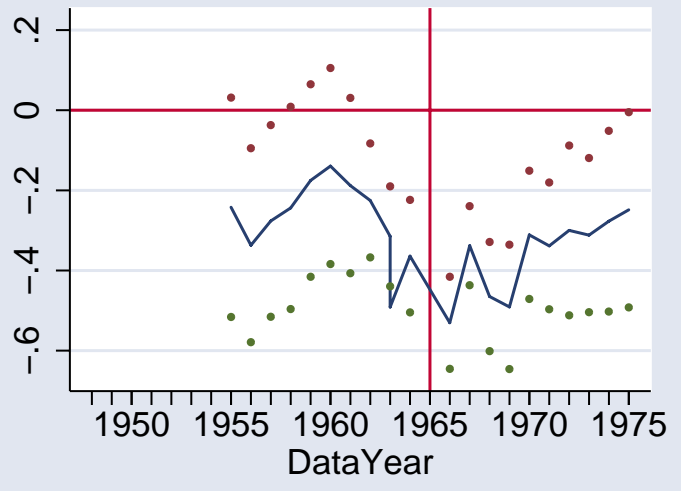

Note: Figure 3 graphs the pattern of the $\lambda_{t}$ coefficients from estimating equation (1) for the dependent variable given above each graph; all dependent variables are in logs. The scale of the graph is normed in the reference year (1965) to the average difference in the dependent variable between the south and west relative to the north and northeast. The dots show the 95 percent confidence interval on each coefficient relative to the reference year (1965). 


\section{Appendix A: The American Hospital Association (AHA) Historical Data.}

The American Hospital Association Data are taken from the hospital-level data published in the annual August issue of Hospitals: The Journal of the American Hospital Association.

\section{$\underline{\text { Sample definition and time period }}$}

The results are based on receipt of hospital surveys sent to every AHA-registered hospital in the United States. Receipt of the survey is generally required by February for inclusion in the August issue. For flow data (such as expenditures, employment, and patient days), the survey asks hospitals to report for the 12month period ending September $30^{\text {th }}$ of the year prior to the publication year. For stock data (such as the number of beds, or whether the hospital has various facilities or technologies) it is less clear whether it is as of the survey response (i.e. before February of the publication year) or as of September $30^{\text {th }}$ of the prior year. In all of the analysis, I take the year to be the year prior to publication year. Thus, for example, the 1966 data was published in the 1967 August issue of Hospitals and contains flow data for the period October 11965 through September 30 ${ }^{\text {th }}$ 1966, and stock data as of the fall of 1966.

The response rate to the AHA surveys for the period I am studying is over 90 percent in all the years in question (and often above 96 percent). ${ }^{33}$ Virtually all responding hospitals report bed information, and about 93 percent report information on admissions, patient days, and employment. However, only about 83 percent report payroll or total expenditure information; this is probably because such information is considered more proprietary by the hospital. Hospital expenditures are therefore likely to be measured with more error than the other variables.

Variable definitions are consistent over the period used in this study. They are as follows:

Total Expenditures: Total expenses for a 12 month period.

- These consist of payroll and non payroll expenses. Non-payroll expenses include employee benefits, professional fees, depreciation expenses, interest expenses, and other expenditures (supplies etc.). Non-payroll expenses are about 40 percent of total hospital expenditures.

- The AHA does not report hospital revenue during this time period; estimates of Medicareinduced changes in hospital expenditures therefore do not include any effect of the market-wide change in health insurance on the markup charged for health care services.

Payroll Expenditures: Payroll expenses for a 12-month period.

- Payroll expenses include all salaries and wages (for both full time and full-time equivalents of part-time personnel) except for those paid to interns, residents and students.

Beds: Excludes Bassinets

Employment: Includes all paid personnel (both full-time and full-time equivalents for part-time personnel) except residents, interns and students.

- Paid personnel do not include most physicians, since most physicians are not directly employed by the hospital.

- The 1964 data indicate that just over half of the paid personnel are devoted to the "professional care of patients" (i.e. nurses and technicians); the remainder are divided among a variety of custodial and administrative functions. (This breakdown is not available in most years).

Admissions: Total inpatient admissions for a 12-month period, excludes newborns.

Average Daily Census: Average number of inpatients receiving care each day during a 12-month period; excludes newborns.

- Patient Days measure used in paper is created by multiplying average daily census by 365

\footnotetext{
${ }^{33}$ This is considerably higher than the response rate in more recent decades, and likely reflects the fact that the earlier surveys asked for considerably less detailed information than more recent surveys.
} 


\section{Appendix B: Predictions from the Rand HIE for the impact of Medicare on hospital spending}

To calculate what the Rand HIE estimates imply for the predicted impact of Medicare, I use the Rand estimates of the impact of moving from no insurance to a policy that approximates the original Medicare policy. Medicare hospital insurance originally imposed a $\$ 40$ deductible (in 1965 dollars) and then no copayment for the first 60 days. ${ }^{34}$ Since the average length of a hospital stay for the elderly in 1963 was only 20 days - and only 5 percent of elderly hospital visits entailed stays of more than 60 days - it seems reasonable to approximate Medicare's hospital coverage as having a 0 co-pay ${ }^{35}$. Accounting for the fact that Medicare introduced an 25\% co-pay after 60 days would only decrease the implied spending effect of Medicare further).

The results from the Rand experiment suggest that the effect of an individual moving from no insurance to a policy with no co-pay and a $\$ 125$ deductible (in 1983 dollars, which is equivalent to a $\$ 40$ deductible in 1965 dollars) would be to increase hospital spending by 37 percent . These estimates can be found in Keeler et al. (1988) and Newhouse et al. (1993), especially pages 129- 130. It is important to note that the Rand experiment placed limits on the maximum out of pocket spending that the individual could have; these out of pocket maximums may affect the spending response. Keeler et al. (1988) therefore describe how the cost-sharing effects in the absence of such limits can be estimated from the data from the Rand experiment. The 37 percent estimated increase in hospital spending associated with moving from no insurance to a Medicare-like policy represents the estimate when there are no limits on the individual's out of pocket payments.

Therefore, the implied effect from the Rand experiment of moving 75 percent of the elderly from no insurance to Medicare's hospital insurance would be to increase hospital spending among the elderly by 28 percent. According to the 1963 Survey of Health Care Utilization, the elderly constituted 20 percent of total hospital spending. As a result, the Rand estimates imply that Medicare would increase total hospital spending for all ages by about 5.6 percent.

It is more difficult to perform a similar comparison to the implied impact of Medicare from the Rand HIE on hospital admissions or patient days. Unlike for spending, estimates for health care utilization were not calculated to allow computation of the "pure" effects of cost-sharing separately from the effects of limits to maximum out of pocket expenditures. Nonetheless, the results of cruder comparisons still suggest that the implied impact of Medicare from the Rand experiment on hospital admissions would be substantially lower than what I have estimated here (see e.g. Newhouse et al., 1993 Table 3.2).

\footnotetext{
34 The deductible was set to be the cost of a day of hospital care (Somers and Somers, 1967).

${ }^{35}$ Author's estimates on elderly length of stay are based on the 1963 Survey of Health Service Utilization and Expenditures.
} 